UCRL-ID-125089

\title{
Geomechanical Properties of Topopah Spring Tuff at the 0.5-m Scale: Preliminary Results of Compression Tests at Elevated Temperature
}

\author{
Stephen C. Blair \\ Patricia A. Berge
}

This is an informal report intended primarily for internal or limited external distribution. The opinions and conclusions stated are those of the author and may or may not be those of the Laboratory.

Work performed under the auspices of the U.S. Department of Energy by the Lawrence Livermore National Laboratory under Contract W-7405-ENG-48. 


\section{DISCLAIMER}

This document was prepared as an account of work sponsored by an agency of the United States Government. Neither the United States Government nor the University of California nor any of their employees, makes any warranty, express or implied, or assumes any legal liability or responsibility for the accuracy, completeness, or usefulness of any information, apparatus, product, or process disclosed, or represents that its use would not infringe privately owned rights. Reference herein to any specific commercial product, process, or service by trade name, trademark, manufacturer, or otherwise, does not necessarily constitute or imply its endorsement, recommendation, or favoring by the United States Government or the University of California. The views and opinions of authors expressed herein do not necessarily state or reflect those of the United States Government or the University of California, and shall not be used for advertising or product endorsement purposes.

This report has been reproduced directly from the best available copy.

Available to DOE and DOE contractors from the Office of Scientific and Technical Information P.O. Box 62, Oak Ridge, TN 37831

Prices available from (423) 576-8401

Available to the public from the National Technical Information Service

U.S. Department of Commerce 5285 Port Royal Rd. Springfield, VA 22161 


\section{Contents}

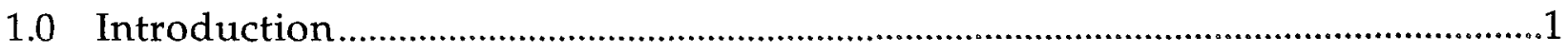

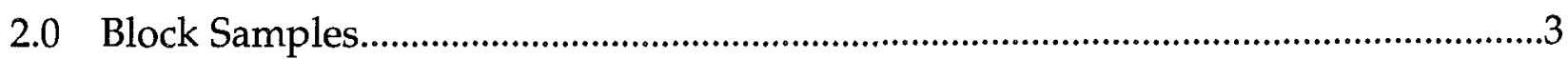

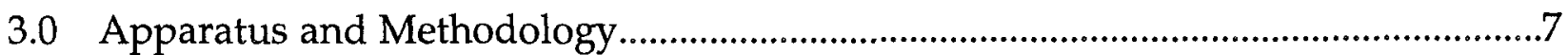

3.1 Loading Frame and Vertical Stress Measurement .............................................7

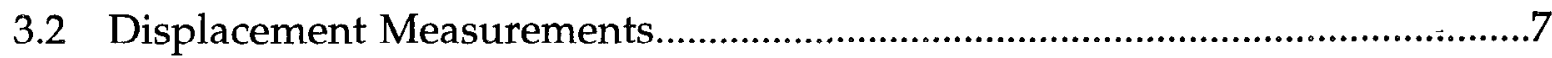

3.3 Heaters and Temperature Measurements..........................................................10

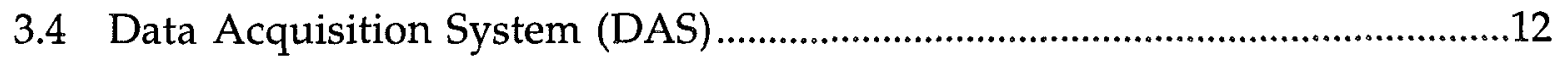

3.5 Velocity Measurements....................................................................................15

3.5.1 Measurement Apparatus .........................................................................16

3.5.2 Measurement Procedure .......................................................................18

3.5.3 Apparatus Testing and Calibration ............................................................19

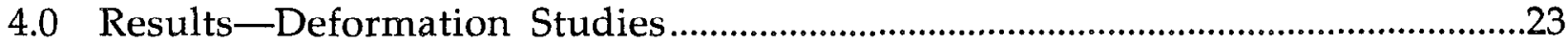

4.1 Description of Load Path .......................................................................................23

4.2 Rock Mass Deformation at Ambient Temperature............................................26

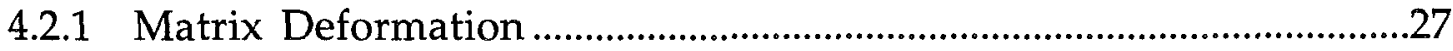

4.2.2 Deformation of an Individual Fracture................................................28

4.3 Testing at Elevated Temperature .........................................................................32

4.3.1 Temperature Distribution........................................................................32

4.3.2 Deformation at Elevated Temperature .................................................36

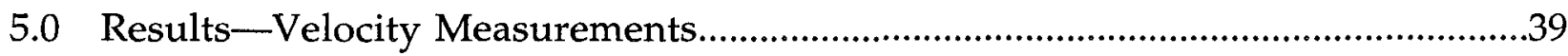

5.1 Comparison of Velocity and Temperature Results.....................................47

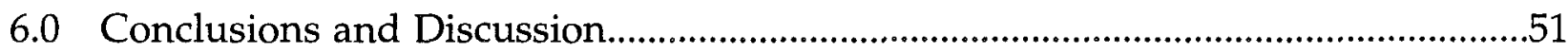

Acknowledgments......................................................................................................52

Appendix. Observations of Fractures in Small Block Samples SB-2 and SB-3............53 


\section{Geomechanical Properties of Topopah Spring Tuff at the 0.5-m Scale: Preliminary Results of Compression Tests at Elevated Temperature}

\subsection{Introduction}

This report presents preliminary results of laboratory testing of a small block sample of Topopah Spring Tuff. This is the first in a series of tests on small block samples. The purpose of these tests is to investigate the thermal-mechanical, thermal-hydrological, and thermal-chemical response of the rock to conditions similar to the near-field environment (NFE) of a potential nuclear waste repository. This report presents preliminary results of deformation and elastic-wave velocity measurements on a $0.5-\mathrm{m}$ scale block of Topopah Spring tuff tested in uniaxial compression and at temperatures to $85^{\circ} \mathrm{C}$.

Data at this scale are needed to provide input to models used for analysis of the repository, as data from smaller samples commonly tested in the laboratory do not provide information on fracture behavior, and very few data sets are available from in situ rock masses. Moreover, tests at this scale have the benefit that known boundary and environmental conditions can be imposed on a rock sample that contains multiple fractures, while field data are often poorly constrained because of inherent limitations on boundary conditions, sampling intervals, and material characterization.

These tests are the first of a series of tests designed to study coupled processes in the near-field environment of a nuclear waste repository. Results provide new deformation and elastic-wave velocity data that provide an approximation of totalrock-mass mechanical properties and behavior for welded tuff units that contain fractures and vugs, and guidance for input values used in equivalent continuum models of a repository. These results provide constraints on how the flow and transport properties of the rock in the very near-field region of a repository may change as the temperature and stress fields change over time.

This report contains descriptions of the small block samples (Section 2) and of the methodology used in the testing (Section 3), presents data for deformation (Section 4) and elastic-wave velocities (Section 5) measured on one small block at elevated temperature and pressure, and finally presents conclusions and a discussion of the results. 


\subsection{Block Samples}

This section describes the preparation of block samples for laboratory tests. The small block samples were excavated from the Topopah Spring tuff exposure at Fran Ridge. Rough blocks and boulders excavated from the site were cut into rectangular prisms having dimensions of several tens of centimeters. To date, four block samples have been prepared-samples SB-1,2,3, and 4. These samples all exhibit the typical Topopah Spring tuff fabric of subparallel vugs in pink and gray densely welded tuff. Samples SB 1, 3, and 4 were prepared from boulders excavated from the Large Block Test (LBT) site; sample SB-2 was prepared from a block of rock excavated from near the base of the Large Block. Sample dimensions and sources are tabulated in Table 1.

Sample SB-1 had approximate dimensions of $64 \mathrm{~cm} \times 32 \mathrm{~cm} \times 25 \mathrm{~cm}$ and contained several high-aspect-ratio vugs that were oriented roughly subparallel with the foliation. The sample was cut so that the vugs and foliation were parallel to the longest dimension of the sample and perpendicular to one of the shorter dimensions. Figures 1(a) and (b) show examples of large vugs in SB-1.

Sample SB-2 was prepared from rock excavated from the Large Block site at Fran Ridge. This is the largest sample obtained to date. The surface expressions of fractures in this sample were mapped; fracture data for three of the faces are shown in Fig. 2, which shows that this sample contains a single throughgoing fracture that is partially healed.

Samples SB-3 and SB-4 are similar in size to sample SB-1 and have similar characteristics.

Table 1. Dimensions of Small Block samples (cm).

\begin{tabular}{|c|c|c|c|c|}
\hline Sample & $x$ & $Y$ & $\mathbf{Z}$ & Source \\
\hline SB-1 & 64 & 32 & 25 & $\begin{array}{l}\text { Cut from boulder, subplanar vuggy } \\
\text { zone oriented parallel to the } X-Y \\
\text { plane }\end{array}$ \\
\hline SB-2 & 56.6 & 62.2 & 64.0 & $\begin{array}{l}\text { Excavated from near base of Large } \\
\text { Block }\end{array}$ \\
\hline SB-3 & 26.2 & 24.5 & 49.0 & $\begin{array}{l}\text { Cut from boulder, subplanar vuggy } \\
\text { zone oriented parallel to the long- } \\
\text { direction plane }\end{array}$ \\
\hline SB-4 & 18 & 33 & 58 & Cut from boulder \\
\hline
\end{tabular}


This report presents data obtained during thermal-mechanical testing of sample SB-1. Sample SB-3 is currently being prepared for testing. Fractures on the surfaces of samples SB-2 and SB-3 have been mapped and recorded in digital form. Figure 3 shows a perspective plot of sample SB-3, and additional plots and descriptions of samples SB-2 and SB-3 are contained in the Appendix.

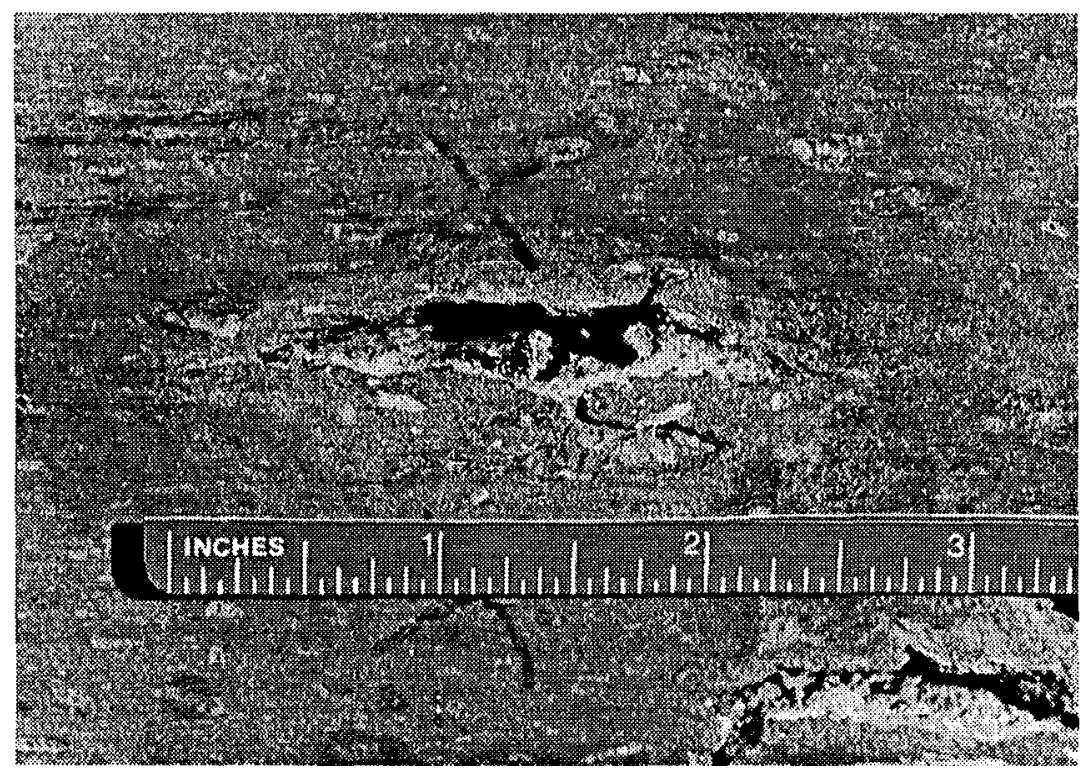

Fig. 1(a). Open vug in sample SB-1.

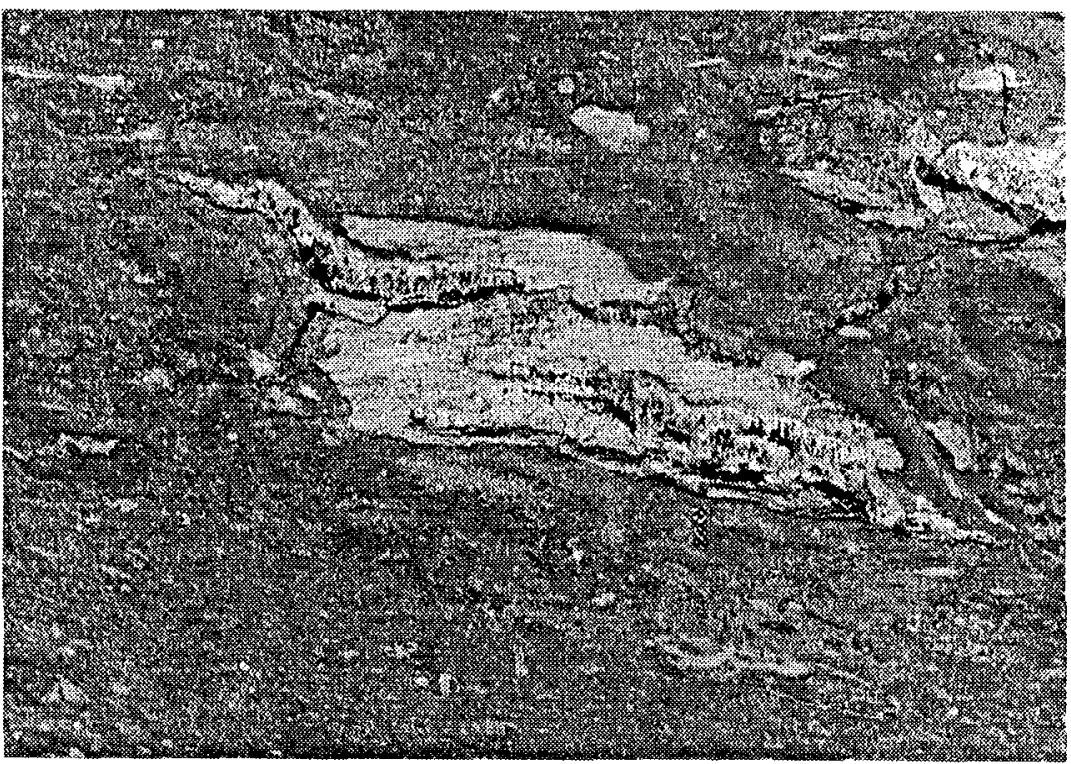

Fig. 1(b). Filled vug in sample SB-1. 


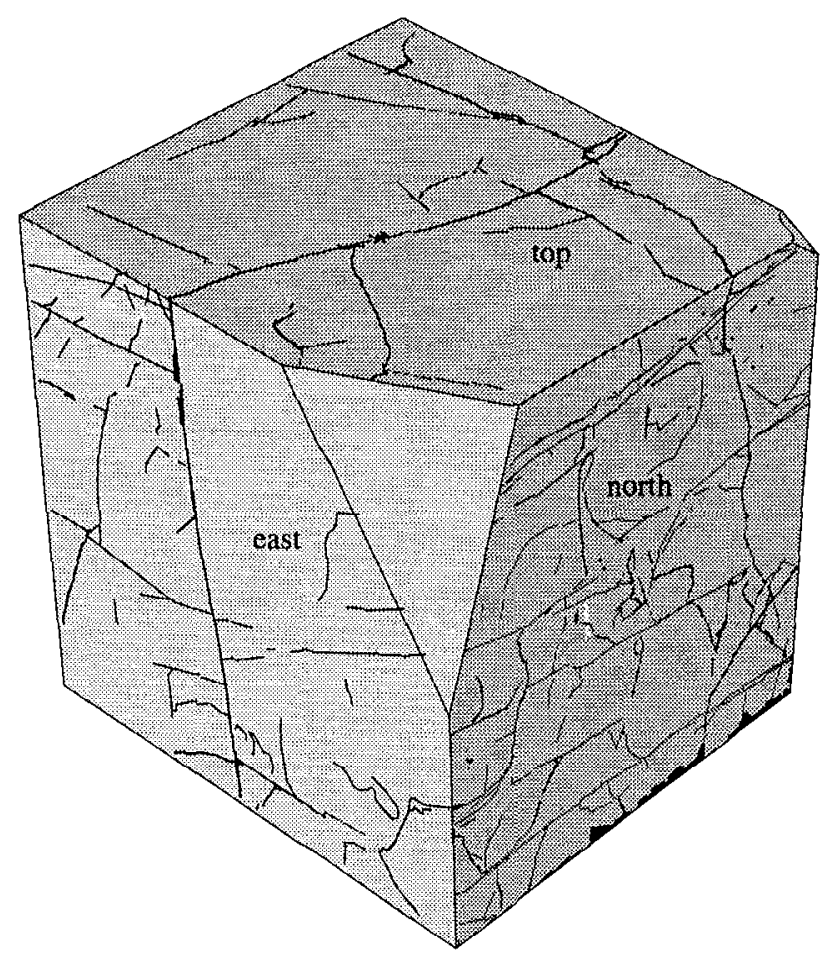

Fig. 2. Fracture map of SB-2, showing three faces and throughgoing fracture.

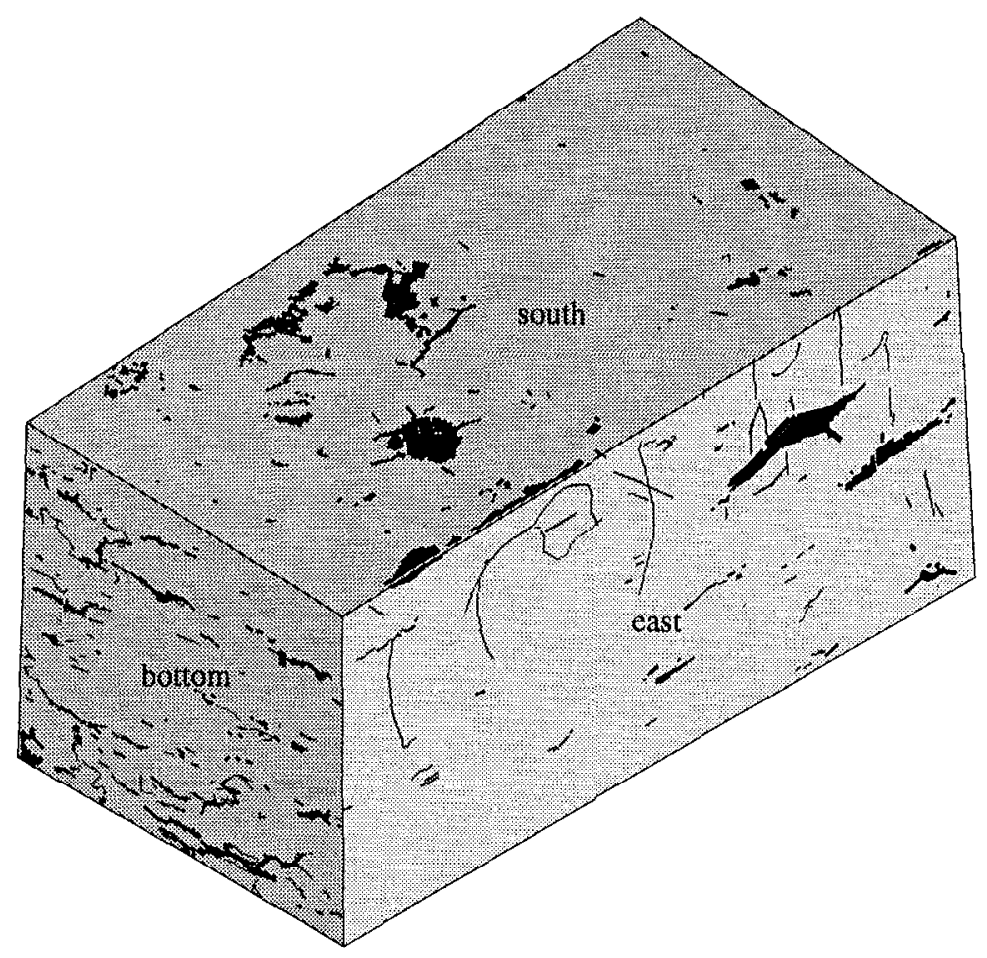

Fig. 3. Locations of the fractures and vugs on the south, east, and bottom faces of SB-3. Notice the alignment of the fractures and vugs on the bottom and east faces. 


\subsection{Apparatus and Methodology}

This report presents preliminary results of deformation and elastic-wavevelocity measurements on a $0.5-\mathrm{m}$-scale block of Topopah Spring tuff tested in uniaxial compression and at temperatures to $85^{\circ} \mathrm{C}$. The general geometry for these tests is shown in Fig. 4, and is described in detail in the following sections.

\subsection{Loading Frame and Vertical Stress Measurement}

The apparatus used for testing small blocks in compression is a 300-ton loading frame that can accommodate samples up to $1 \mathrm{~m} \times 1 \mathrm{~m}$ in cross section and $2 \mathrm{~m}$ in height, thus allowing testing of samples up to $2 \mathrm{~m}^{3}$ in volume. This apparatus is shown in Fig. 5. The vertical load is applied via 12 hydraulic actuators that are mounted in the cross-head and operated in tandem. The large sample size afforded by this apparatus allows testing of samples that contain multiple fractures, and heterogeneities on the order of a few tens of centimeters in size. The vertical loading system includes a low-volume, air-driven pump and a metering valve that provides precise control of vertical stress on the small block samples. For all tests conducted in this study, the press was operated in uniaxial compression only. Figure 6 shows sample SB-1 assembled into the test frame. The pressure in the actuators that supplied the vertical load was monitored manually from a pressure gauge and was recorded using the Data Acquisition System (DAS). The vertical stress on the sample was computed using the pressure supplied to the loading actuators, the cross section of the pistons in the actuators, and the horizontal cross section of the sample.

\subsection{Displacement Measurements}

Deformation was measured using linear displacement transducers (direct current displacement transducers or DCDTs). Initially nine displacement transducers were used, but after the first sequence of testing, six more were added. The locations of the transducers are illustrated in Fig. 7. Initial locations of some of the nine original transducers can be seen in Fig. 6. Figure 8 shows how some of the transducers monitored displacement over the entire height of the block while others measured the deformation of individual fractures or zones of unfractured rock matrix. Displacement measured by a transducer was determined from voltages, and strain over the measured length for a given DCDT was then calculated. 
Fig. 4.

Schematic

diagram for

thermomechanical

testing of block

SB-1.

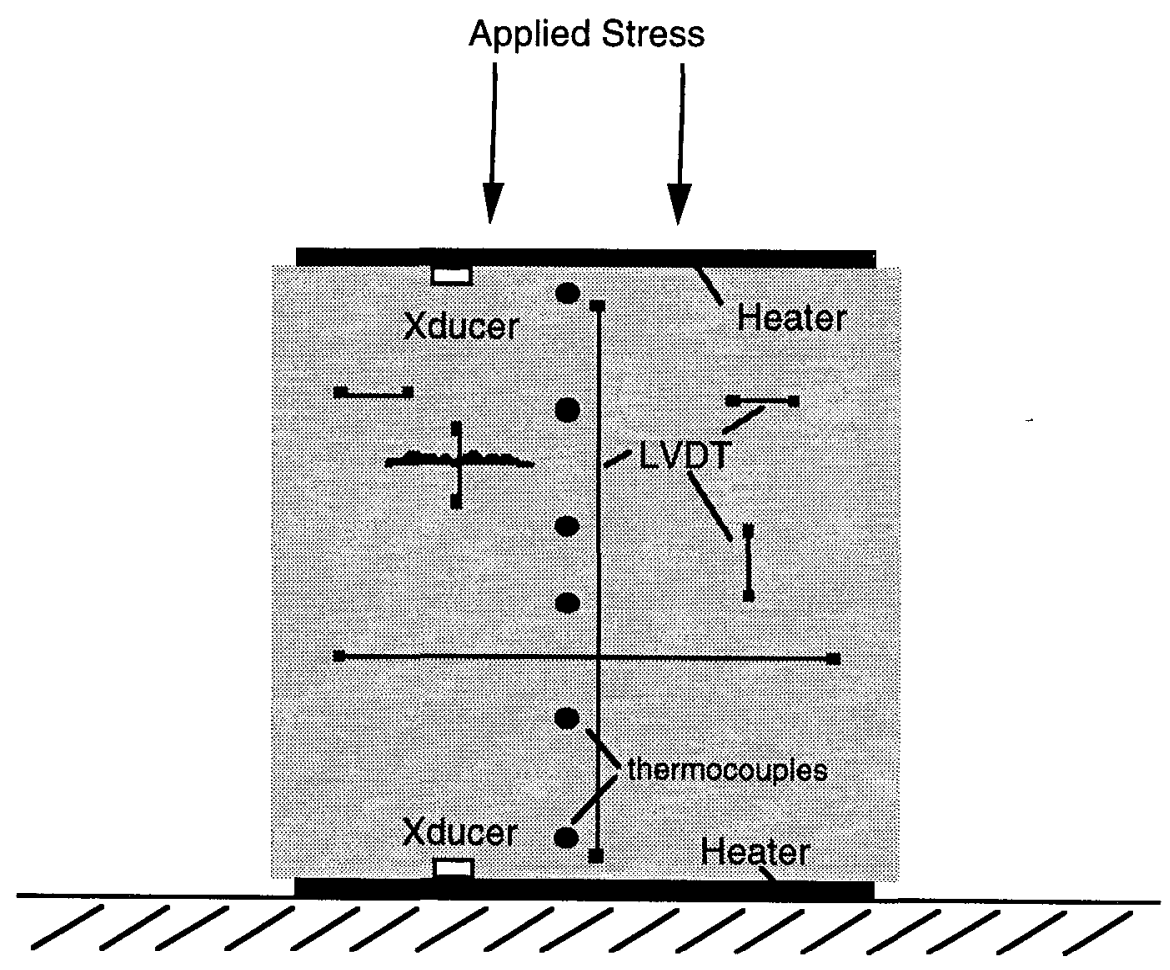

Fig. 5.

Photograph of 300-ton loading frame used for small block tests.

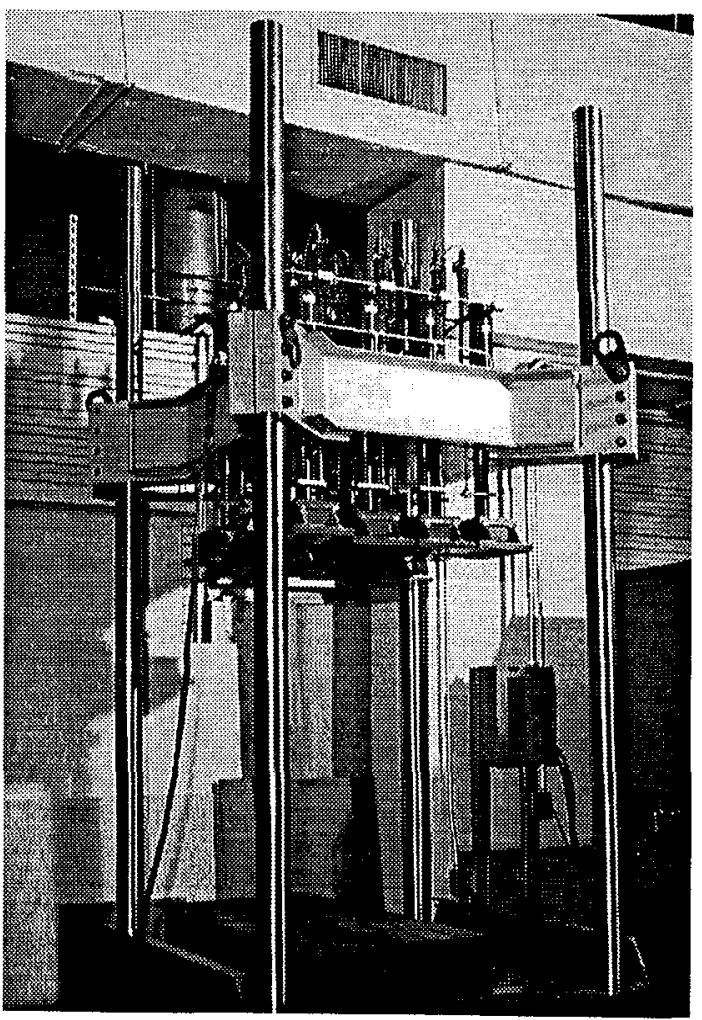




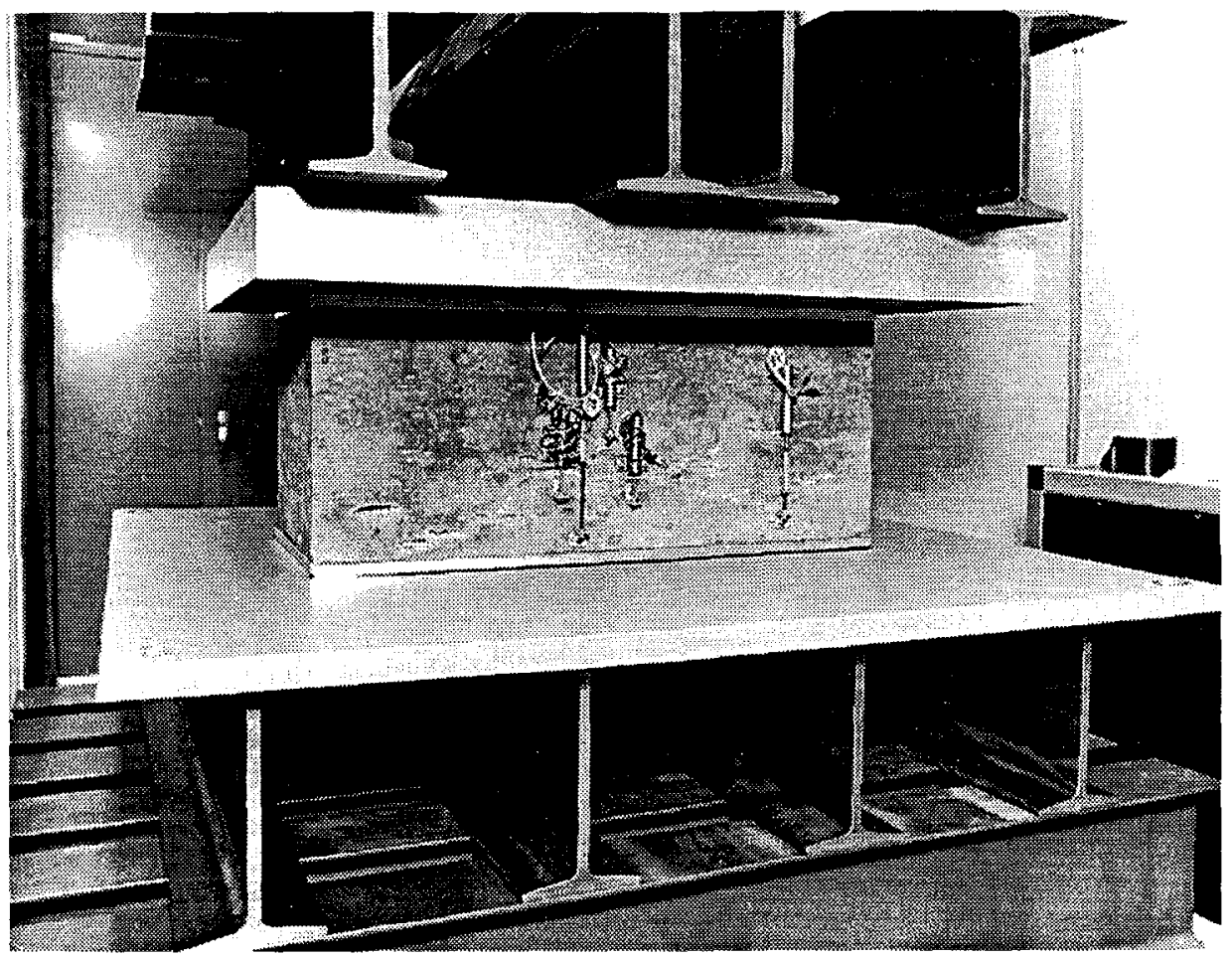

Fig. 6. Sample SB-1 assembled into load frame, prior to test Sequence \#1.

EAST

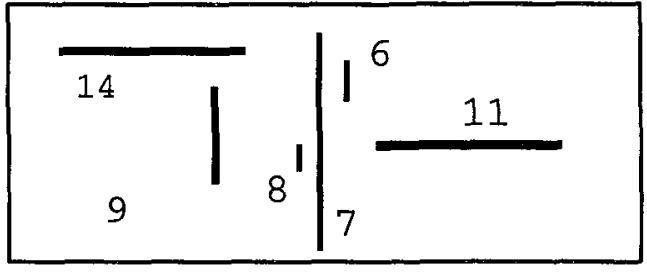

NORTH
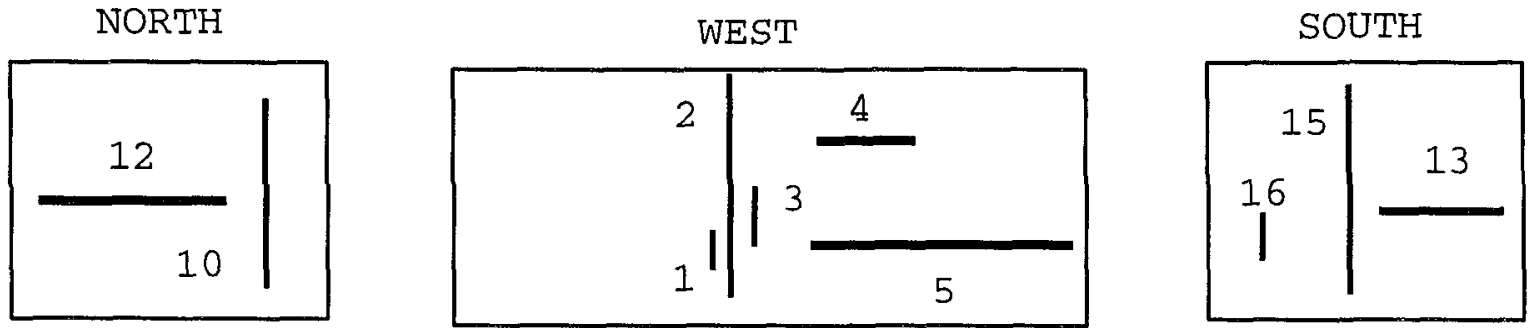

Fig. 7. Displacement transducer locations for sample SB-1. 
Fig. 8. Close-up of displacement transducers, showing how some measure displacement across fractures while others measure matrix displacement or displacement of both fractures and matrix.

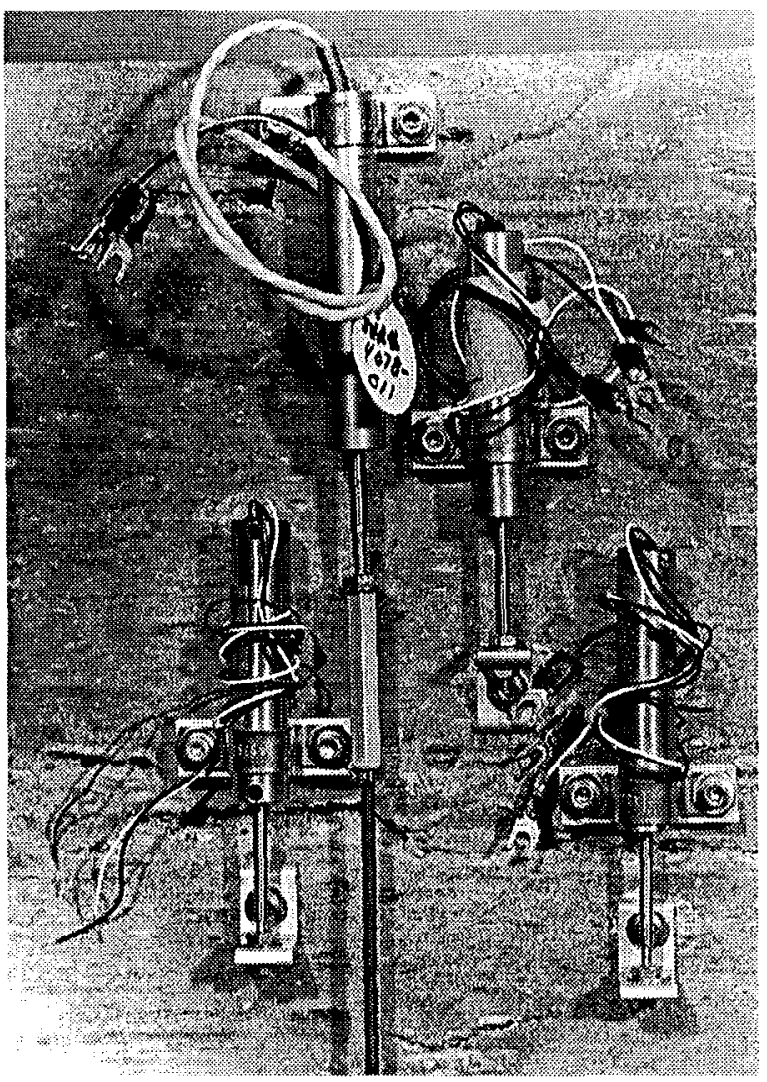

\subsection{Heaters and Temperature Measurements}

Part of the testing described in this report was conducted at elevated temperatures. For the high-temperature tests, the sample was heated from the top and bottom as illustrated in Fig. 4. A heater/insulation stack was placed above and below the sample. The heater/insulation stack consisted of the following components: a 1/16-in. layer of Teflon, heaters, and a 1/16-in. thick copper plate cut to size for the top and bottom surfaces of the sample. Two 15-watt foil heating elements were attached to each copper plate along with a thermocouple to measure the temperature near each heating element, as shown in Fig. 9. This configuration was simulated using the FLAC thermomechanical code, and found to produce nearly uniform temperatures across the block face. The heater plate was separated from the rock surface using a 0.125-in. Teflon sheet. A 4-in. layer of Marinite insulation was placed between the heater plates and the loading platens at the top and bottom of the block. (Marinite is a fiber-reinforced calcium silicate insulating material.) Household roll-type insulation (R30) was wrapped around the entire assembly to insulate the sides of the block. The heaters were powered using a 
manually adjustable power supply. The heating elements were wired in parallel, and an input voltage between 0 and 34 volts was sufficient to heat the block.

Temperature was measured at selected points located along a vertical line near the center of the sample and along a horizontal line in the midplane of the sample. Twelve thermocouples were used; the locations of these thermocouples are illustrated in Fig. 10. Figure 11 shows the thermocouples and DCDTs assembled onto the sample.

Fig. 9. Heater plate for small block tests.

Foil heating elements
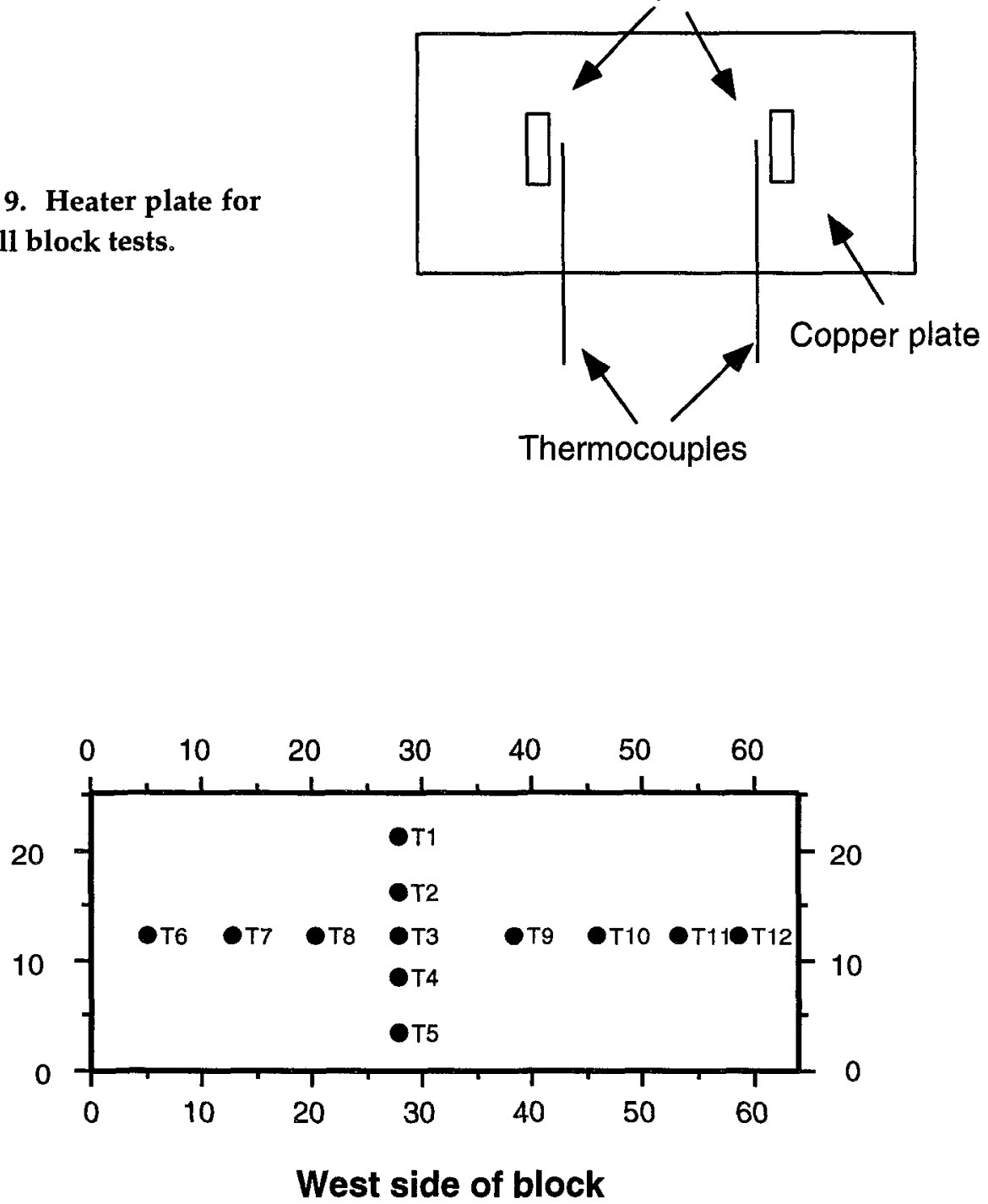

Fig. 10. Locations of thermocouples on sample SB-1. 


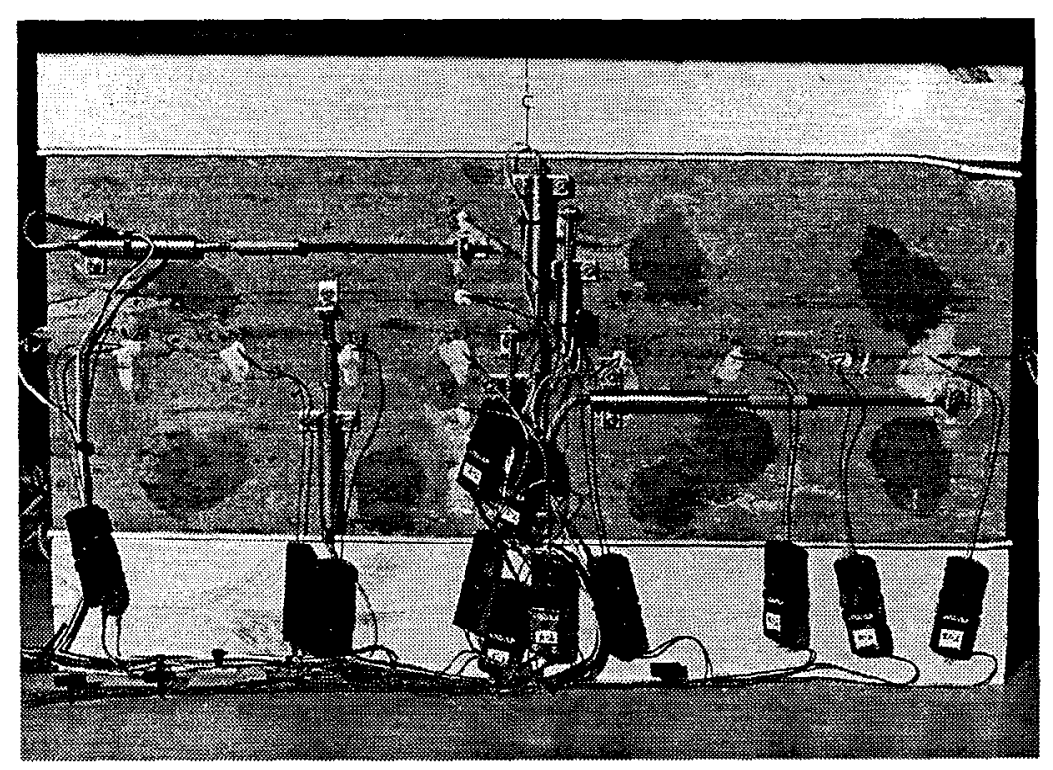

Fig. 11. Photograph of east side of sample SB-1, showing locations of thermocouples and displacement transducers during Sequence \#3. Dark circular areas indicate locations where velocity transducers were mounted.

\subsection{Data Acquisition System (DAS)}

Data from the initial compression experiments conducted at ambient temperature were recorded using a computerized data acquisition system (DAS). The hardware and software used for data acquisition of pressure and displacement data incorporated 16-bit I/O boards from National Instruments. These were installed on a Macintosh computer and a virtual instrument (vi) program was written (using National Instruments LabView software v3.1) to acquire and process the data. This program stores pressure and displacement data, together with the date and time, at user-prescribed intervals in a digital file on the hard disk drive. This system also provides for manual control of the pressure, and setting a switch on the DAS provides slowly increasing pressure. Other information needed for QA records of the tests is also stored in the file. Figure 12 shows the on-screen user interface for the data acquisition program.

This configuration of the DAS was found to be inadequate for testing at elevated temperature; prior to that testing it was upgraded. A National Instruments Multiplexing system was added (SCXI 1000) along with some associated hardware. In addition, the LabView software was upgraded. The DAS system used for testing at elevated temperature is shown schematically in Fig. 13. Figure 14 shows the screen interface for the new DAS. 


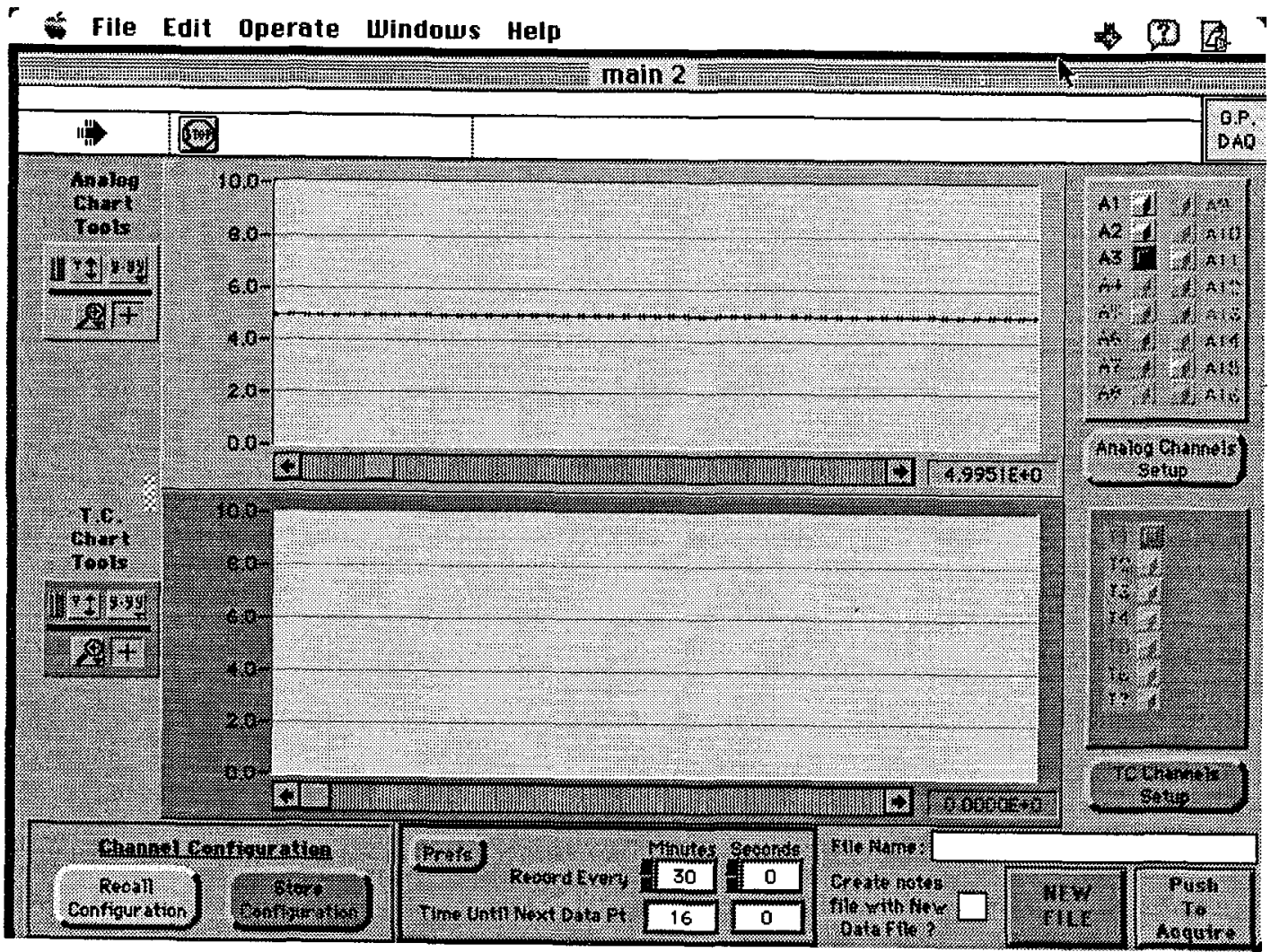

Fig. 12. On-screen user interface for Data Acquisition System used during Sequence \#1 and \#2.

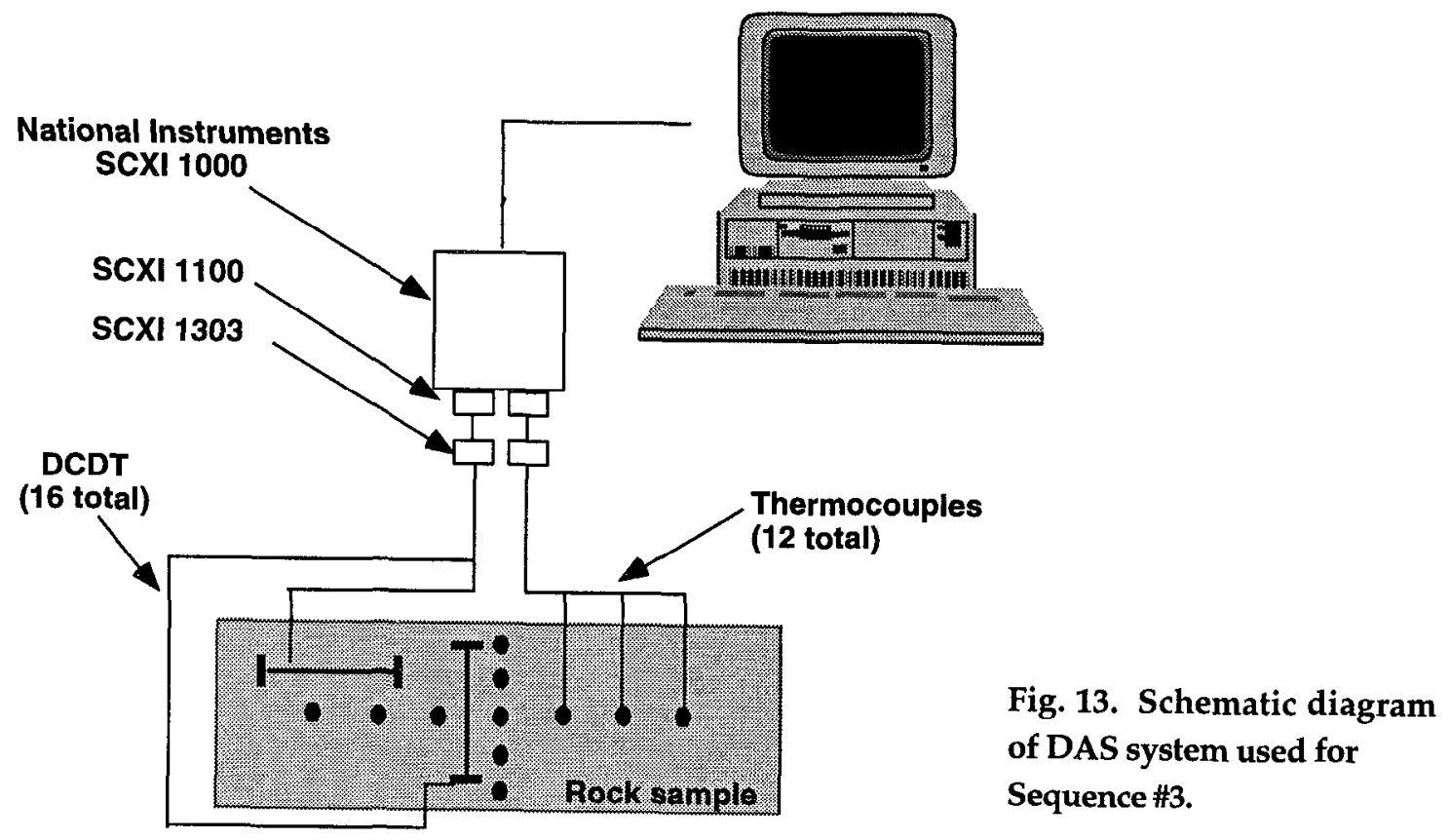




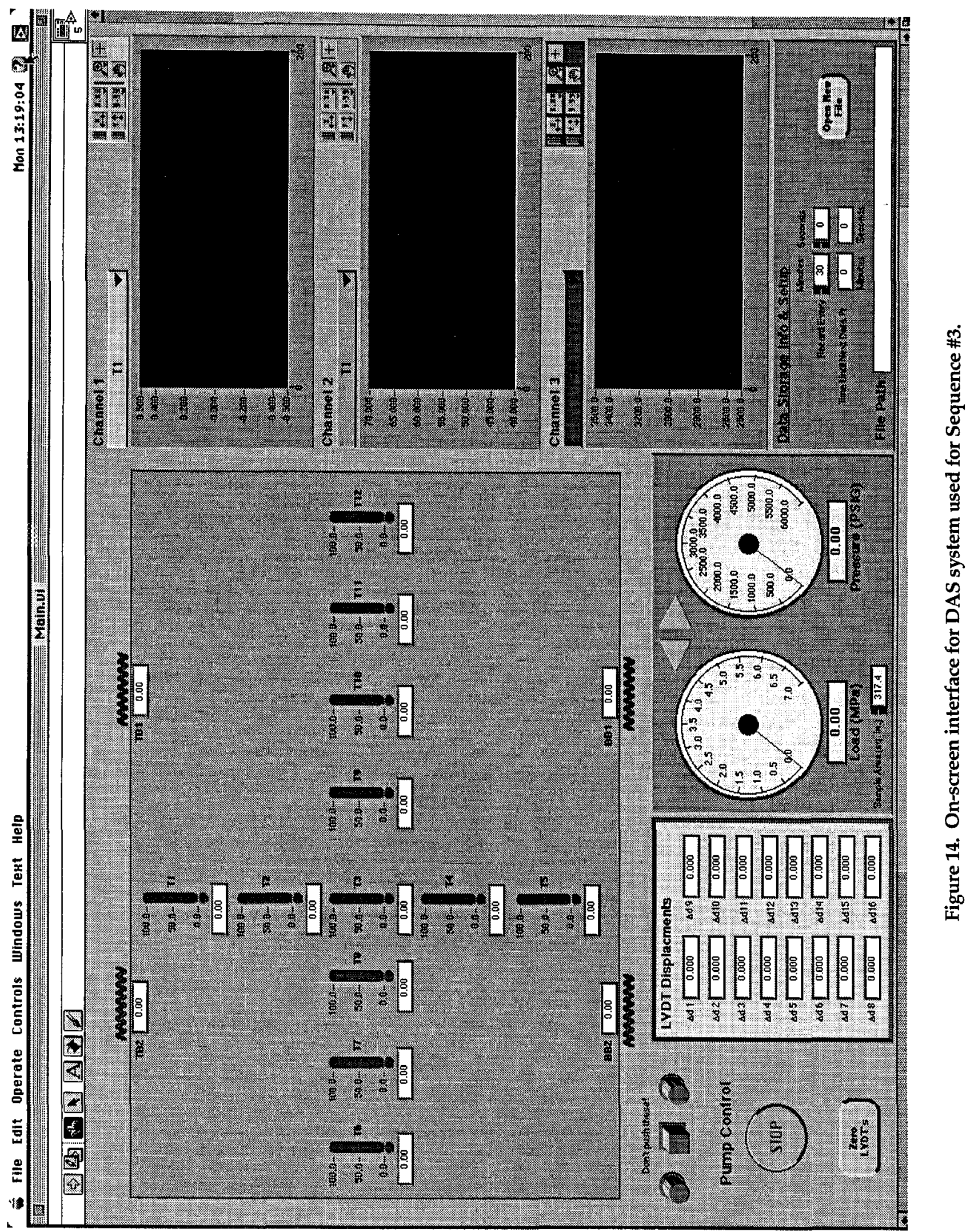




\subsection{Velocity Measurements}

Compressional-wave velocities were measured in many locations for horizontal wave propagation through sample SB-1. For each measurement, the source and receiver transducers were positioned on opposite faces of the block, in alignment to measure horizontal propagation along the shortest direct path through the block (see Fig. 15). It was not possible to measure velocities in the vertical direction because the block was sitting in the load frame and there was no access to the top or bottom of the block. Some parts of the block were inaccessible because of the displacement transducer instrumentation. Velocity measurements were made for all accessible parts of the block, with a measurement spacing of about one or two wavelengths. Initial measurements were made at ambient pressure and temperature conditions, and velocity measurements were repeated at elevated stress and temperature conditions. Results of the measurements are described in a later section of this report. Frequency dependence was not investigated because of cost considerations.

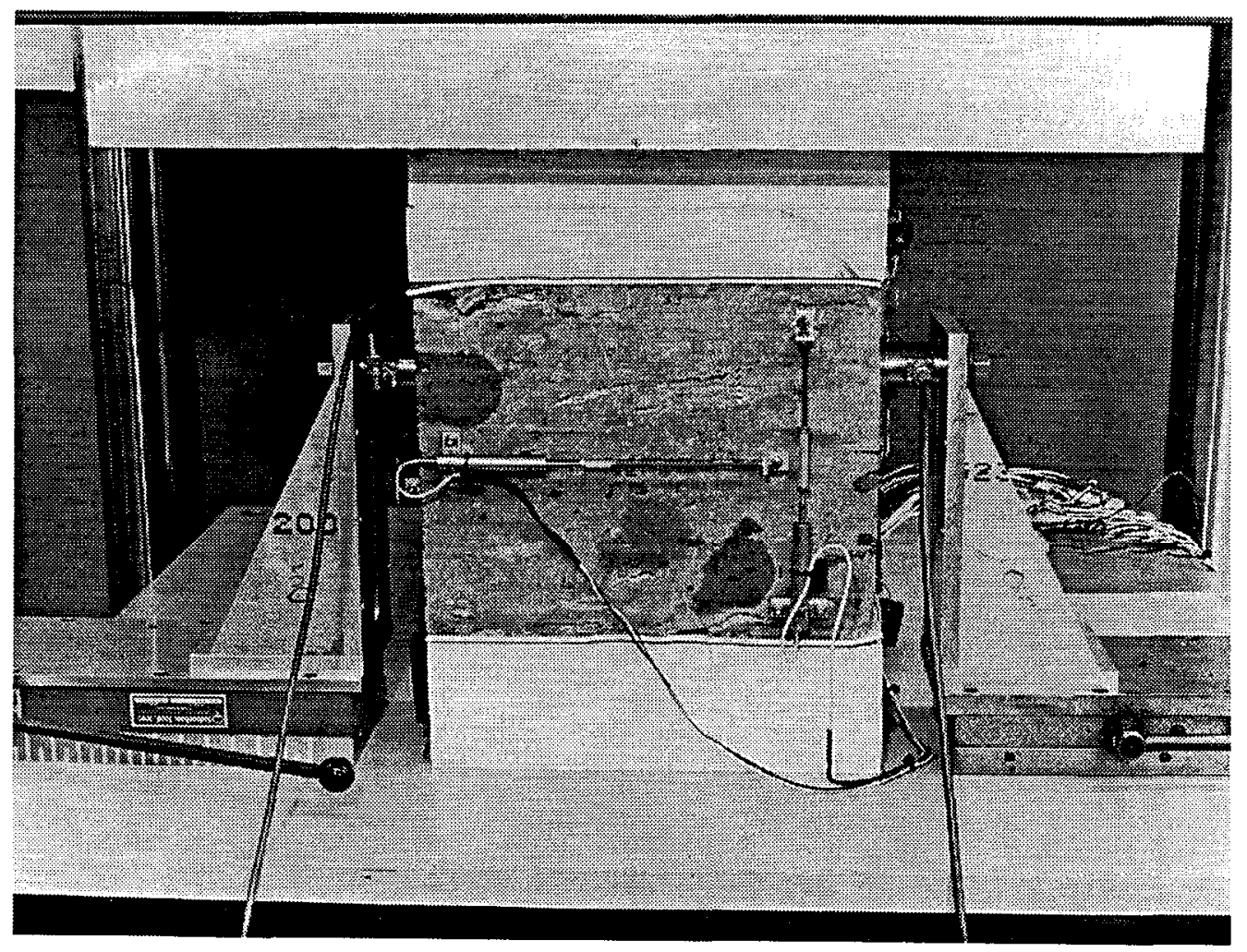

Fig. 15. Velocity transducers positioned on sample SB-1. 


\subsubsection{Measurement Apparatus}

The laboratory apparatus for the velocity measurements is designed to serve several purposes in a cost-effective manner. Figure 16 shows a schematic of the experimental apparatus configured for measuring elastic-wave velocities for a small block. Multipurpose requirements include the ability to measure velocities on scales varying from a few centimeters to about $1 \mathrm{~m}$, so that the same apparatus can be used for core samples and for small blocks of rock. (Standard ultrasonic experiments measure velocities on scales of millimeters or centimeters, but distances of $1 \mathrm{~m}$ exceed the capabilities of standard laboratory apparatus.) In addition to the velocity measurements, acoustic emissions can be monitored using the same equipment. The apparatus is designed to allow measurements to be made on tuff samples subjected to uniaxial stress and heating to $200^{\circ} \mathrm{C}$.

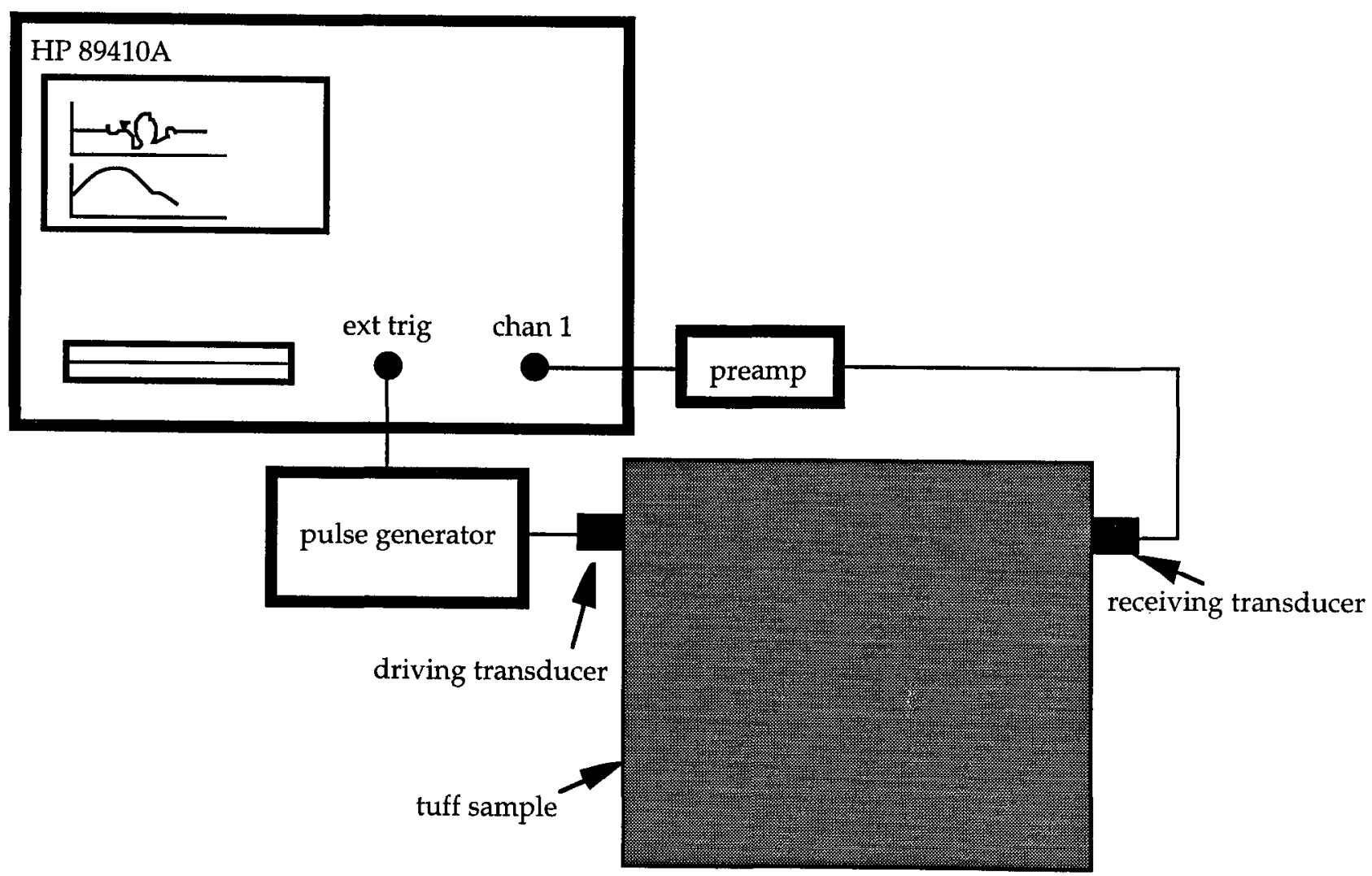

Fig. 16. Schematic diagram of apparatus for measuring elastic-wave velocities. 
The problem of the large measurement scale is solved by using a sophisticated data acquisition system that has the ability to trigger an external source and record a pulse many hundreds of times in less than a second. The HP89410A signal analyzer leased from Hewlett-Packard can repeat the measurement rapidly and add up all the transmitted signals to reduce uncertainty due to random noise. This stacking allows reliable measurements of weak signals, such as elastic waves traveling through a meter of rock.

The state-of-the-art HP hardware uses 16-bit digital input/output, whereas other available systems use fewer bits and have poorer measurement accuracy and precision. The instrument is programmable and has a built-in disk drive, allowing display and processing of data as it is collected. This improves data quality and minimizes data loss.

Since acoustic emissions and elastic-wave velocity measurements in small blocks of tuff involve frequencies of a few tens to a few hundreds of kilohertz, the transducers had to be sensitive to these frequencies and able to withstand temperatures above $200^{\circ} \mathrm{C}$. They also had to be inexpensive since they would not be reusable if it were necessary to grout them onto the rock to improve the signal quality. To meet these requirements, piezoelectric transducers were purchased from Wolff Engineering Corp. These were $100-\mathrm{kHz}$, heavily damped transducers, polarized for compressional waves. They were inexpensive since they do not contain internal preamplifiers. Signal conditioning was provided by an ultrasonic preamplifier manufactured by Panametrics. The preamp had a gain of $60 \mathrm{~dB}$ in the $20 \mathrm{kHz}$ to $2 \mathrm{MHz}$ range. A 60-dB gain increases signal amplitude about 1000 times. This amplification was necessary because while the signal analyzer was programmed to trigger on a source pulse with an amplitude of $1 \mathrm{~V}$, even after amplification by the preamp, the transmitted pulses typically had amplitudes of only a few millivolts to a few tens of millivolts after traveling through many tens of centimeters of tuff. A pulse generator was used for the source. The input wave form was a spike.

The transducers were supported on stands with magnetic bases that could be fixed to a steel plate supporting a small block of tuff in the loading frame. The magnetic bases provided a convenient way to adjust the horizontal positions of the transducers before each measurement while maintaining stable transducer positions during measurements. The height of each transducer above the base of its stand also could be adjusted easily. Behind each transducer was a screw used to push the transducer firmly up against the sample to provide consistent coupling of signal 
energy between the transducer and the rock. Transducer coupling was further improved by spreading a thin film of water-soluble, polystyrene ultrasonic coupling gel over the face of the transducer before each measurement. For measurements made at elevated temperatures, a silicone vacuum grease was used as the coupling gel. This procedure made it unnecessary to grout the transducers to the rock, and made it possible for measurements to be taken in many locations around a small block of tuff.

\subsubsection{Measurement Procedure}

The velocity measurements were conducted by programming the signal analyzer to trigger on a pulse from an external source, stack a large number of transmitted signals (typically several thousand for measurements in tuff), and display the time series and frequency spectrum so that an arrival could be identified accurately enough to compute the compressional-wave velocity. Typical output waveforms were approximately sinusoidal, with frequencies of about $100-200 \mathrm{kHz}$ and long wavetrains. In the time domain, resolution was about $0.4 \mu \mathrm{s}$, and frequencies between the $\mathrm{DC}$ level and $2 \mathrm{MHz}$ could be resolved to about $5 \mathrm{kHz}$. For each velocity measurement, the time series was displayed initially using a long record (usually 100 or $200 \mu \mathrm{s}$ ) so that the compressional-wave arrival could be located. The signal analyzer was then programmed to use a trigger delay (usually about $70 \mu \mathrm{s}$ ) and a short record length (typically 10 or $20 \mu \mathrm{s}$ ) to display the beginning of the compressional-wave arrival in greater detail. The onset of the compressional wave was determined from this time series displayed on the signal analyzer screen. The frequency spectrum, signal amplitude and noise amplitude on the time series, and signal-to-noise ratio were used to assess the measurement uncertainty. For tuff, after stacking several thousand signals, most measurements had signal-to-noise ratios between 2:1 and 4:1 and uncertainties in arrival time identification of about $0.4 \mu \mathrm{s}$. Most of the recorded signal energy was in the $100-$ to $200-\mathrm{kHz}$ range. Only time-series data were used quantitatively for this report; analysis of the frequency spectra for determining the attenuation properties of the tuff will be part of future work. Frequency analysis can provide information about how energy is scattered by inhomogeneities in the tuff and about relative sizes and concentrations of cracks, vugs, and other inhomogeneities. 


\subsubsection{Apparatus Testing and Calibration}

In order to determine the system delay for the velocity measurement apparatus, compressional waves were measured in aluminum cylinders of different lengths. Figure 17 shows the time series and frequency spectrum measured for a 2.5inch (63-mm) aluminum cylinder. The peak energy is near $120 \mathrm{kHz}$, and the onset of the compressional wave arrival is at about $11.7 \mu \mathrm{s}$. Averaging 100 signals produces a time series with a signal amplitude of about $0.5 \mathrm{~V}$ and a signal-to-noise ratio of about 8:1. Similar measurements were made using four other aluminum samples. The aluminum measurements had an uncertainty of only about $0.2 \mu \mathrm{s}$ in the picked arrival times, because of the excellent data quality. Repeated measurements on one of the aluminum samples showed that coupling problems contributed an additional uncertainty of up to $0.4 \mu \mathrm{s}$. Note that aluminum does not attenuate the signal very much compared with the inhomogeneous and highly attenuating tuff. Metals behave as elastic solids, with typical quality factors several orders of magnitude larger than quality factors for porous or cracked rocks. (A high quality factor corresponds to low attenuation.) Another difference is that the aluminum samples were about the size of a wavelength, whereas the signals had to travel for tens of wavelengths through the tuff block. Thus an excellent signal-tonoise ratio is achieved in aluminum by stacking 100 signals, but about a thousand signals must be stacked in order to obtain a good signal-to-noise ratio in tuff.

Figure 18 shows the recorded travel times for compressional waves in these aluminum samples. A standard linear regression on these data points produces a line whose intercept gives the time correction for the measurement system, to. This system delay is fairly small, only about $1 \mu \mathrm{s}$. The inverse of the slope of the regression line is the compressional wave velocity, $\mathrm{Vp}$, about $6.6 \mathrm{~mm} / \mu \mathrm{s}$ for these aluminum samples. These aluminum measurements had an uncertainty of about $\pm 0.6 \mu \mathrm{s}$. Tuff samples are expected to have a greater uncertainty ( \pm a few $\mu \mathrm{s}$ ) because the coupling is not as good and the signal-to-noise ratio is lower. The path lengths are much longer in large tuff samples, which implies that a few microseconds of uncertainty may not be as significant as in the small aluminum samples. Uncertainties in velocities arise from uncertainties in the picked arrival times (typically $\leq 1 \mu$ s for the tuff sample) and uncertainties from the system delay ( $<1 \mu \mathrm{s})$. Note that a combined uncertainty of $\pm 2 \mu$ s would translate into a small velocity uncertainty of about $\pm 0.1 \mathrm{~mm} / \mu \mathrm{s}$ for a typical measurement (velocity $\sim 4 \mathrm{~mm} / \mu \mathrm{s}$, pathlength $\sim 300 \mathrm{~mm}$ ) in the tuff block. 


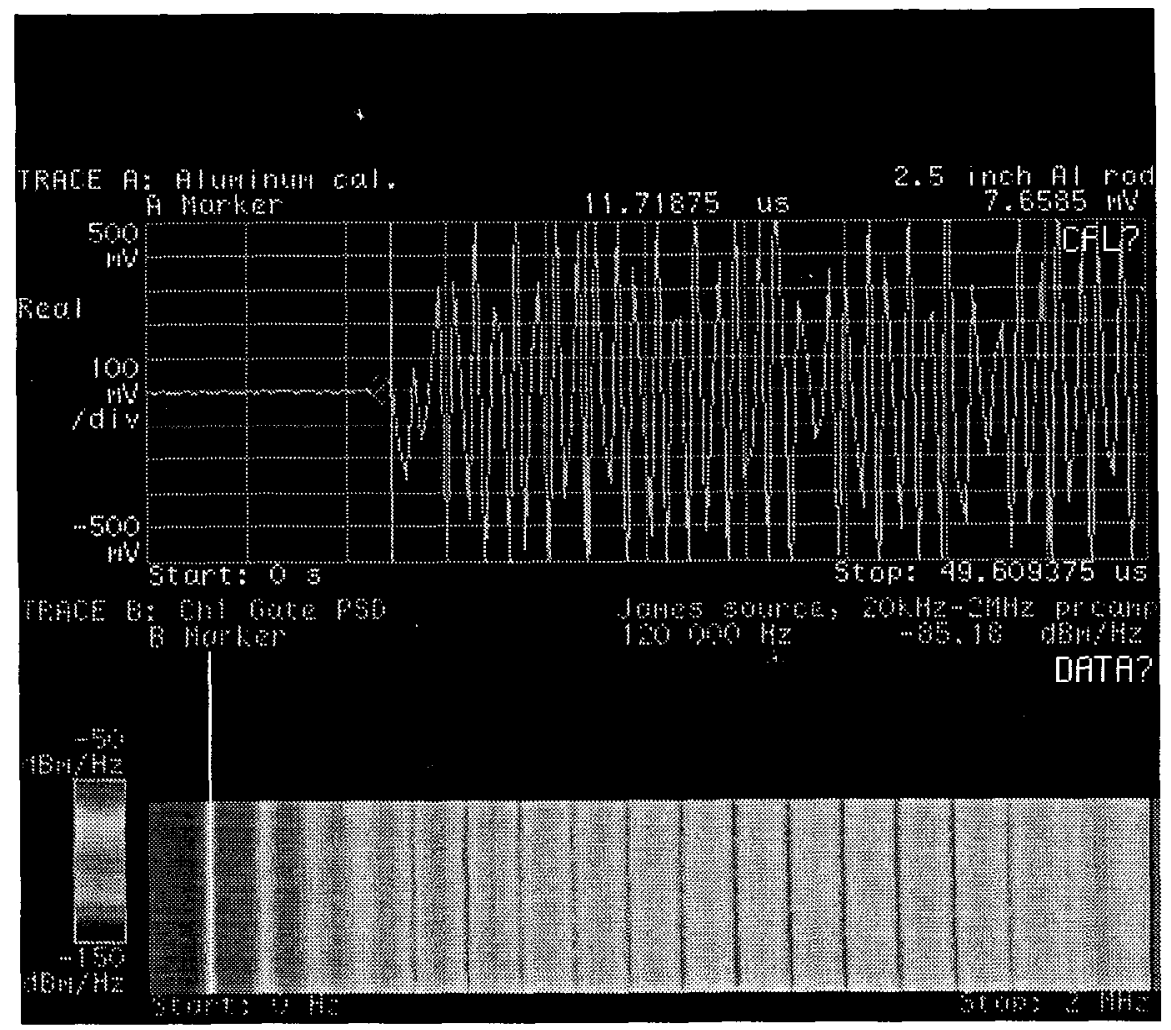

Fig. 17. HP signal analyzer screen, showing time series and frequencies for velocity measurement of aluminum calibration sample.

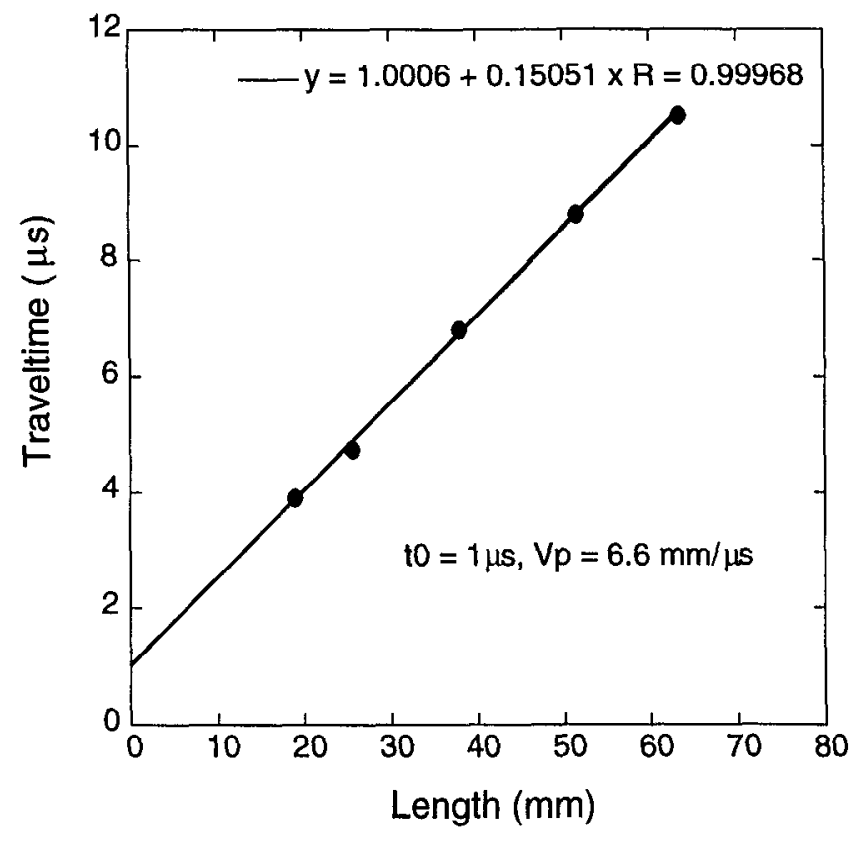

Fig. 18. Plot of travel time as a function of distance traveled, for compressional waves in aluminum samples. 
For purposes of testing the system on a larger sample than the aluminum calibration samples, compressional wave velocities were measured in two directions through a small piece of Topopah Spring tuff that had been cut from a Fran Ridge boulder. The signal-to-noise ratio was less than 2:1 for a 255-mm path length and 1000 stacked signals. No arrival could be identified precisely for this measurement. Stacking several thousand signals improved the signal-to-noise ratio only slightly, with a signal level of only about $3 \mathrm{mV}$. (Improvement in the signal-to-noise ratio does not follow a simple relationship to the number of stacked signals when the signal is weak and coupling is poor.) Applying a thick layer of polystyrene coupling gel resulted in a signal-to-noise ratio of about 2:1 with a signal level of about $10 \mathrm{mV}$. This measurement had an identifiable compressional-wave arrival at about 59.4 $\pm 0.4 \mu$ s. Most of the energy had frequencies below $150 \mathrm{kHz}$. 


\subsection{Results-Deformation Studies}

\subsection{Description of Load Path}

Several loading/unloading cycles were imposed on the block. Initially, a loading sequence (Sequence \#1) was imposed that consisted of a series of four loading/unloading cycles in which the maximum compressive stress, $\sigma_{1}$, was increased by approximately $2 \mathrm{MPa}$ in each successive cycle, until a maximum compressive stress of approximately $8 \mathrm{MPa}$ was applied. Displacement parallel to the applied stress was monitored at nine locations on the vertical surfaces of the block, with some of the transducers mounted across discrete fractures and/or vugs, and others monitoring displacement in unfractured regions as well as over the entire height of the block. Upon review of the data from Sequence \#1, six additional displacement transducers were added to the block, and the loading/unloading cycles were repeated (Sequence \#2). Compressional-wave travel-times were measured after Sequence \#2. For clarity each cycle in a test was labeled with a letter; thus Sequence \#1 includes load cycles $1 \mathrm{a}, 1 \mathrm{~b}$, etc. The load path used in the second of the two tests is shown in Fig. 19. The purpose of the cyclic, incremental loading was to (a) evaluate the testing apparatus, as it had not been used in this configuration before, and (b) evaluate hysteresis in the mechanical deformation from cycle to cycle. Test cycles performed and the maximum stress for each cycle are listed in Table 2.

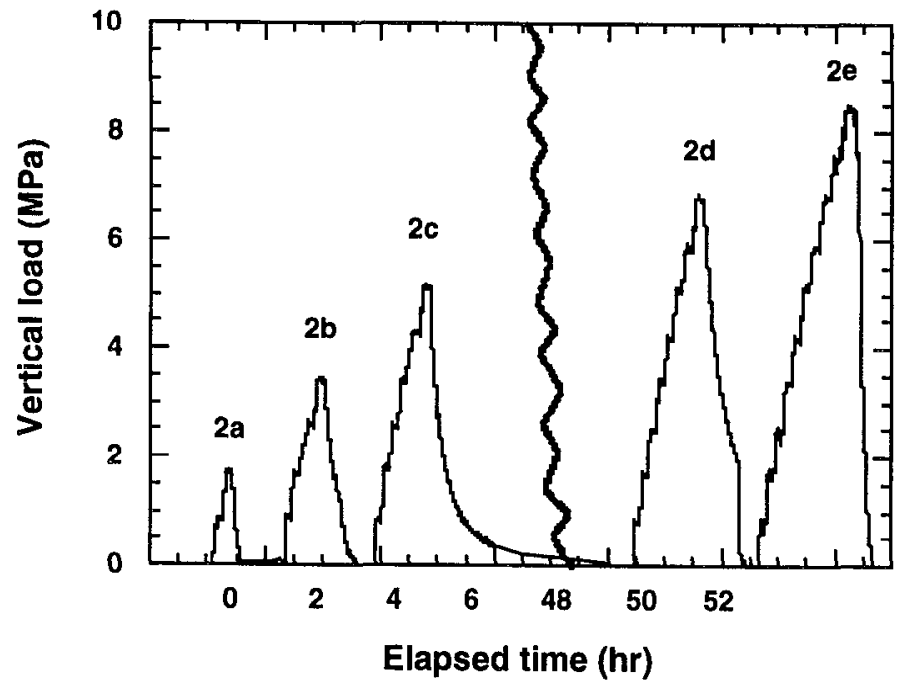

Fig. 19.

Vertical load vs time for Sequence \#2. 
Table 2. Summary of compression Sequences \#1 and \#2.

\begin{tabular}{ccc}
\hline Test & Cycle & Max. vertical stress (MPa) \\
\hline Sequence \#1 & $1 \mathrm{a}$ & 2.0 \\
& $1 \mathrm{~b}$ & 3.5 \\
& $1 \mathrm{c}$ & 7.0 \\
& $1 \mathrm{~d}$ & 8.5 \\
& & \\
Sequence \#2 & $2 \mathrm{a}$ & 2.0 \\
& $2 \mathrm{~b}$ & 3.5 \\
& $2 \mathrm{c}$ & 5.2 \\
& $2 \mathrm{~d}$ & 7.0 \\
& $2 \mathrm{e}$ & 8.5 \\
\hline
\end{tabular}

For Sequence \#1, nine displacement transducers were mounted on the block and these were recorded using the automated DAS discussed in the previous section. The transducers were arranged to provide information on deformation of the entire vertical dimension as well as across specific fractures and vugs, and for regions of unfractured matrix material, as well as for regions containing fractures (see Fig. 8). It is important to note that in this sample, many of the fractures and vugs are subparallel and occur in a more or less planar zone seen in the bottom central part of the sample in Fig. 6. For this test we oriented the sample so that the vertical compressive stress would act in the direction normal to this subplanar zone of fractures and vugs. During this test, the pressure on the vertical loading rams was recorded manually by reading the pressure off a gauge on the system and then entering this information into the data set at the appropriate time using the comment facility of the software. For Sequence \#2, six additional displacement transducers were added to the surface of SB-1 (see Fig. 7) and the loading ram pressure was recorded automatically. Results for Sequences \#1 and \#2 were very similar; only data from Sequence \#2e will be discussed in detail, later in this report.

A third sequence (Sequence \#3) of loading/unloading cycles was performed that included cycling stress at temperatures of about 50 and $85^{\circ} \mathrm{C}$. Prior to this sequence, 12 thermocouples were mounted in the sample, and 6 of the displacement transducers were reconfigured to monitor horizontal deformation. During Sequence \#3 the sample was held at constant stress while temperature was slowly changed and/or compressional-wave travel times were measured. The stress and temperature history of Sequence \#3 is listed in Table 3, and shown schematically in Fig. 20. 
Table 3. Summary of Sequence \#3 activities.

\begin{tabular}{cl}
\hline $\begin{array}{c}\text { Elapsed time } \\
\text { (hr) }\end{array}$ & \multicolumn{1}{c}{ Activity } \\
\hline 1 & Cycle $\sigma_{1}: 0.1-3.5-0.1 \mathrm{MPa}$ \\
22 & Increase $\sigma_{1}$ to $3.5 \mathrm{MPa}, V_{p}{ }^{\mathrm{a}}$ at $3.5 \mathrm{MPa}$ \\
90 & Cycle $\sigma_{1}: 3.5-8.5-5 \mathrm{MPa}, V_{p}$ at $8.5 \mathrm{MPa}$ \\
98 & Cycle $\sigma_{1}: 5-8.5-5 \mathrm{MPa}, V_{p}$ at $8.5 \mathrm{MPa}$ \\
250 & Increase temperature to $50^{\circ} \mathrm{C}$ \\
330 & $V_{p}$ at $5 \mathrm{MPa}$ \\
495 & Cycle $\sigma_{1}: 5-4-7-5 \mathrm{MPa}, V_{p}$ at $5 \mathrm{MPa}$ \\
1200 & Increase temperature to $80^{\circ} \mathrm{C}, V_{p}$ at $5 \mathrm{MPa}$ \\
1450 & Increase temperature to $85^{\circ} \mathrm{C}$ \\
1500 & Cycle $\sigma_{1}: 5-8.5-5 \mathrm{MPa}$ \\
1530 & Cool to $20^{\circ} \mathrm{C}$ \\
1804 & Cycle $\sigma_{1}: 5-8.5-0.1 \mathrm{MPa}$ \\
\hline${ }^{\mathrm{a}} V_{p}$ indicates compressional-wave velocity measurement.
\end{tabular}

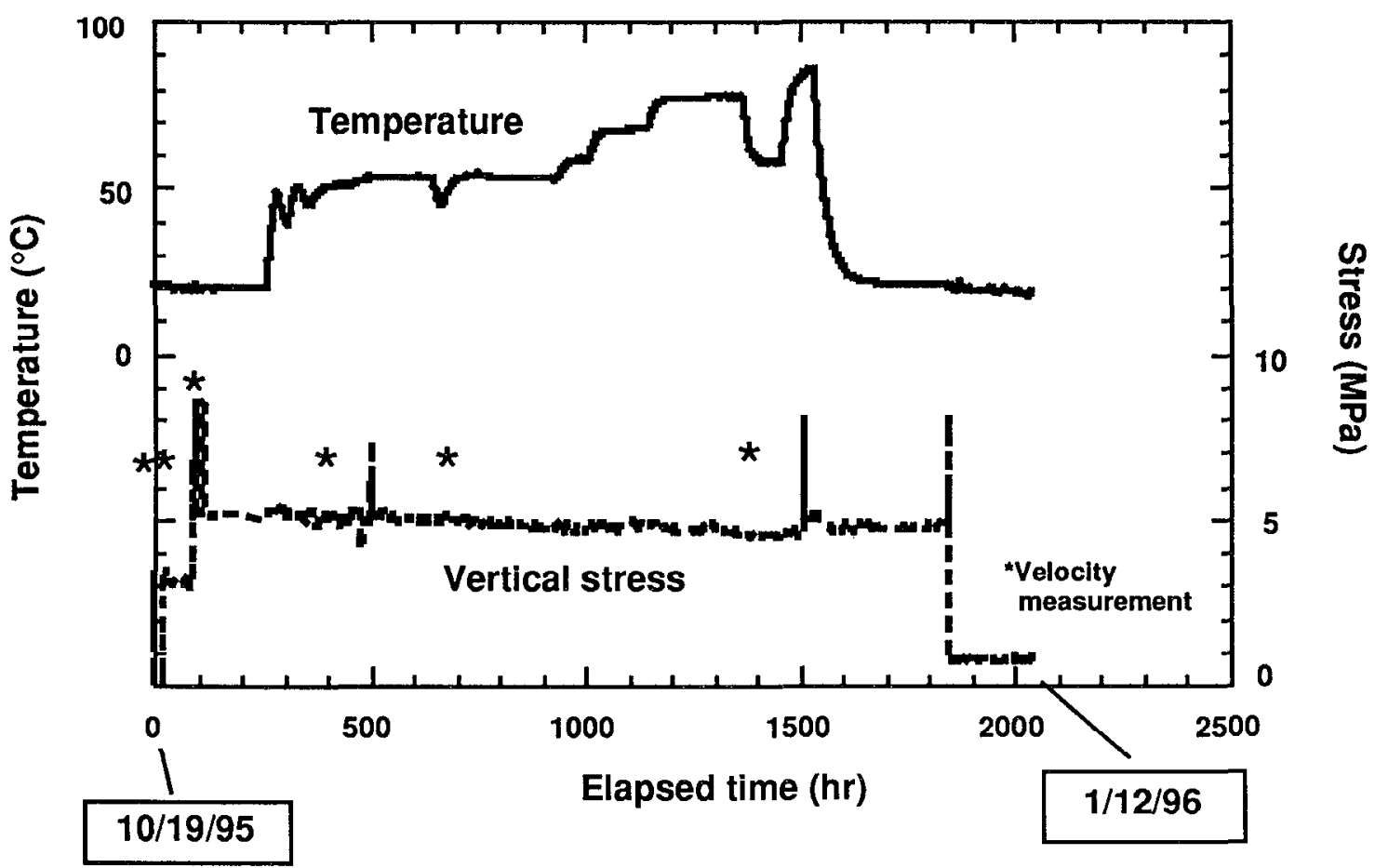

Fig. 20. Temperature and stress history for Sequence \#3. 


\subsection{Rock Mass Deformation at Ambient Temperature}

Testing at ambient temperature included all of Sequence \#1 and \#2 and the first 250 hours of Sequence \#3 (see Figs. 19 and 20). Results for Sequence \#1 and \#2 showed non-linear, repeatable deformation with applied stress, and a stress-strain curve representing deformation in Sequence \#2 is shown in Fig. 21. This figure shows that deformation is nonlinear with increasing stress, and that modulus increases as vertical stress increases above $4 \mathrm{MPa}$. The modulus value computed for vertical stress below $4 \mathrm{MPa}$ is $\sim 4 \mathrm{GPa}$, and that value increases to $\sim 6 \mathrm{GPa}$ as applied stress is raised above $4 \mathrm{MPa}$. These values are considerably lower than modulus values measured on core samples, and reflect the fact that the block contains vugs and fractures. The increase in deformation modulus with increasing vertical stress can be attributed to closure of fractures and vugs that occur in the subhorizontal zone mentioned earlier. Moreover, the curve exhibits the banana shape that is associated with the hysteretic behavior of fractures. The hysteresis shown during the initial stage of unloading is attributed to the cohesion of fractures. The plot shows that the cohesion for this zone is $\sim 1 \mathrm{MPa}$, which is an order of magnitude weaker than values often used in numerical models of rock behavior that incorporate discrete joints and fractures. As the load continues to decrease, the slope of the unloading curve decreases gradually. These data provide guidance for parameter values assigned to the representative element volume (rev) used in equivalent continuum models, and are especially appropriate for analysis of the Topopah Spring tuff at Yucca Mountain because the size of the block (0.5-m scale) is approximately the size of block forming the in situ rock mass.

Fig. 21. Stress-strain curve for two stress cycles applied to sample SB-1 during Sequence \#2.

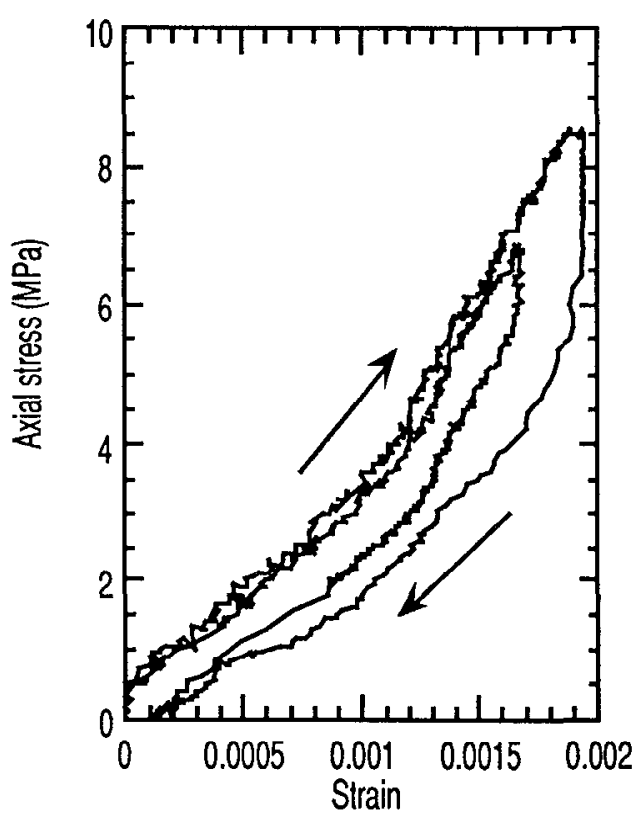




\subsubsection{Matrix Deformation}

A typical stress-strain curve obtained for displacement transducers monitoring matrix areas (areas with no fractures or vugs) is shown in Fig. 22 along with a curve showing strain over the total height of the sample. The stress-strain response is nearly elastic over the range of applied stress; the Young's modulus computed from these data is approximately $7 \mathrm{GPa}$.

Young's modulus values computed for displacement transducers used to monitor deformation over lengths greater than $2.5 \mathrm{in}$. are listed in Table 4 along with the length of the measurement and other relevant information. This table shows that values of Young's modulus fall in two distinct ranges. Values in the range 24$33 \mathrm{GPa}$ are computed for transducers 7 and 9 , located on the east side of the block, and transducer 15, located on the south side. These values are similar to those measured on core samples and are higher than expected for this sample. Values in the range 4.6-7 GPa are reported for transducers 2 and 5 on the west side, transducer 10 on the north side, and transducer 13 on the south side. It is interesting to note that transducer 10 on the south side measures only matrix material, but has a modulus similar to that of transducers measuring across fractures, while both transducers 7 and 15 show high values of Young's modulus even though they measure across fractures and vugs. Additional work is necessary to fully interpret these data. It is important to note that poor data quality for was observed for transducers 7, 9, and 15.

Fig. 22. Stress-strain curves measured for matrix material and for the total height of the sample.

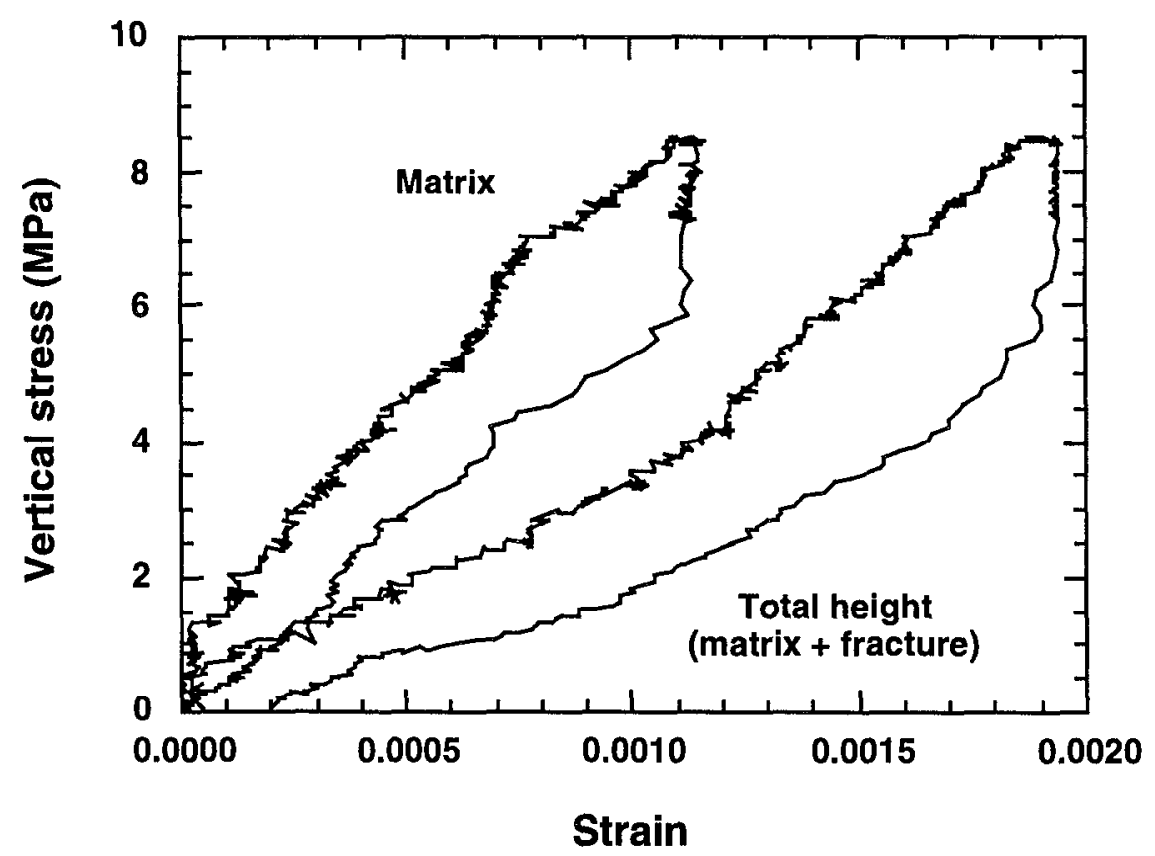


Table 4. Young's modulus values computed for displacement transducers used to monitor deformation over lengths greater than $2.5 \mathrm{in}$.

\begin{tabular}{ccccl}
\hline $\begin{array}{c}\text { Transducer } \\
\text { No. }\end{array}$ & Face & $\begin{array}{c}\text { Gauge length } \\
\text { (in.) }\end{array}$ & $\begin{array}{c}\text { Young's } \\
\text { modulus } \\
\text { (GPa) }\end{array}$ & \multicolumn{1}{c}{ Comment } \\
\hline 2 & W & 8.813 & 6.4 & Fractures + matrix \\
5 & W & 6.688 & 6.6 & Fractures + matrix \\
7 & $\mathrm{E}$ & 8.812 & 33 & Fractures + matrix \\
9 & $\mathrm{E}$ & 3.375 & 25 & Matrix \\
10 & $\mathrm{~N}$ & 7.438 & 6.9 & Matrix \\
13 & $\mathrm{~S}$ & 2.750 & 4.6 & Fractures \\
15 & $\mathrm{~S}$ & 8.032 & 24 & Vugs + matrix \\
\hline
\end{tabular}

\subsubsection{Deformation of an Individual Fracture}

The stress-strain response across one of the fractures during Sequence \#2e is shown in Fig. 23. The deformation data for single fractures is useful for evaluating inputs to discrete element models and some effective continuum models that incorporate the behavior of individual fractures.

The stress-strain curve shows behavior similar to that shown for the entire vertical dimension (Fig. 21). The modulus increases as vertical stress increases above $2.5 \mathrm{MPa}$ from a value of $0.20 \mathrm{GPa}$ to $0.65 \mathrm{GPa}$; this increase is attributed to fracture closure. The stress-strain curve also indicates a value for cohesion of about $1 \mathrm{MPa}$, again considerably less than the value of $7 \mathrm{MPa}$ often used in numerical models. Note that the stress-strain curve does not return to zero strain, indicating that some non-recoverable deformation did occur. This observation indicates permanent deformation of the fractures.

One of the assumptions often made in analysis of fractured rock is that the mechanical response can be decomposed into components due to the matrix material and the fractures, respectively. The data collected during this experiment allow that assumption to be tested. As discussed above, some of the single fracture measurements were made over segments of the length measured for the total block measurement. Displacement transducers 1 and 2 were configured in this manner, with transducer 1 measuring displacement across a fracture, and transducer 2 measuring the displacement over the entire height of the sample (see Fig. 7). Figure 24 shows displacement measured on transducers 1 and 2 as a function of 
time, for Sequence \#2e. This figure indicates that approximately $95 \%$ of the deformation measured by transducer 2 occurs across the fracture monitored by transducer 1. Data for several other fractures (not shown) also indicate this same result. Thus, these data indicate that at this scale, in a rock with vugs and fractures, vuggy zones behave similar to fractures, the decomposition of deformation into matrix and fracture components is valid, and most of the deformation at those stress levels occurs in the fractures.

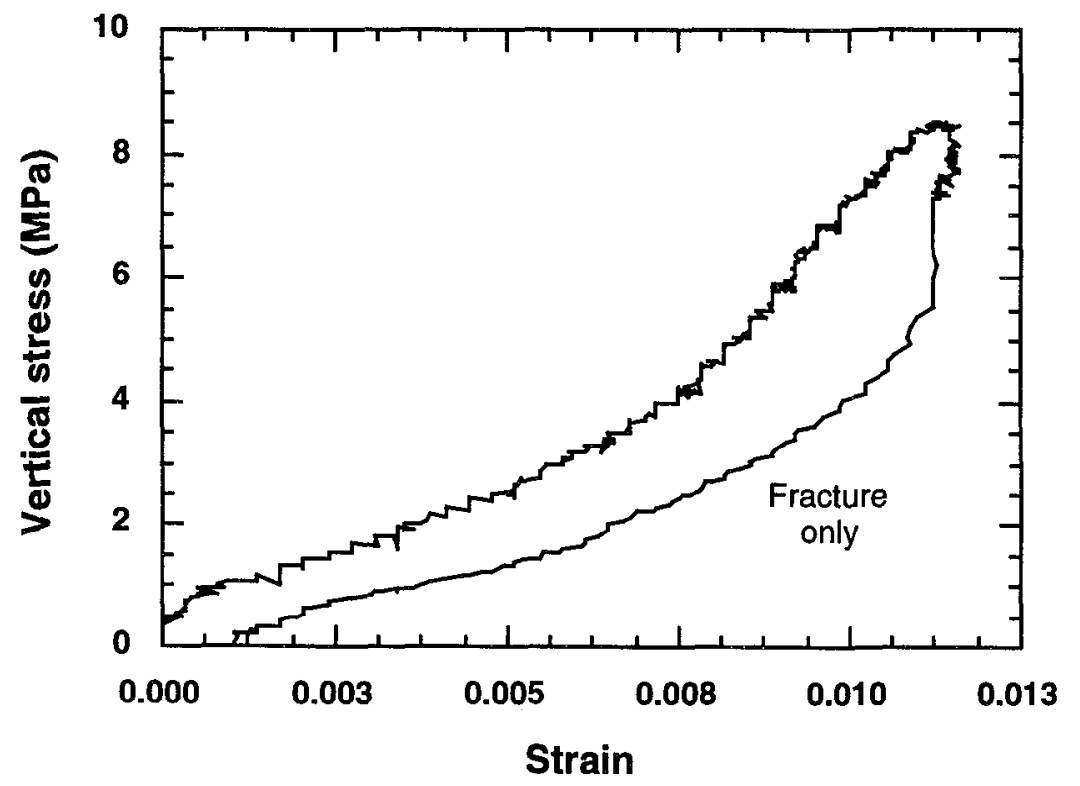

Fig. 23.

Stress-strain curve measured over a discrete fracture.

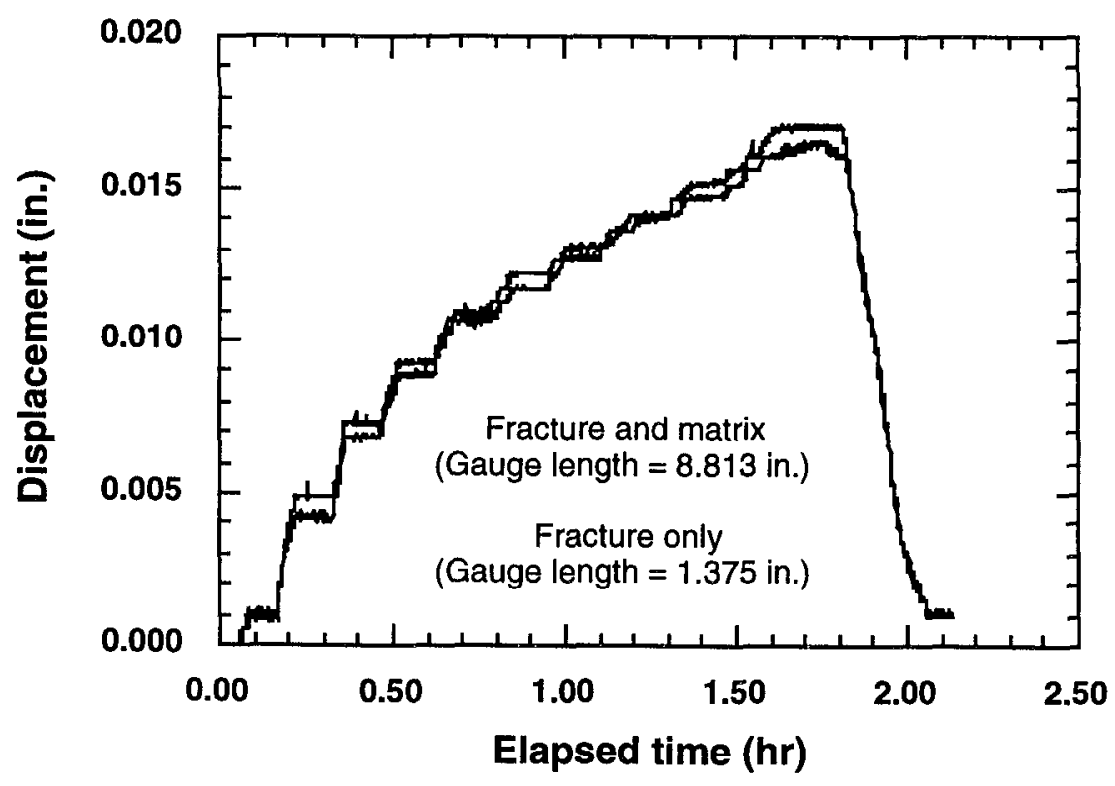

Fig. 24.

Displacement measurements for the total height (fracture + matrix) and for a fracture only. This shows that $\sim 95 \%$ of the deformation occurred across the fracture. 
Stress-strain behavior observed during a portion of Sequence \#3 is shown in Fig. 25 along with the stress-strain behavior from one of the cycles shown in Fig. 21. Figure 25 shows that stress-strain behavior for Sequence \#3 at stresses less than $4 \mathrm{MPa}$ ( 1 and $22 \mathrm{hr}$ ) matched closely with that for Sequence \#2. However, when stress was raised above $4 \mathrm{MPa}$, the deformation curve for Sequence \#3 diverged significantly from that observed for Sequence \#2. It is important to note that, as shown in Table 3, loading of the sample in Sequence \#3 was done over a long period. A stress of $3.5 \mathrm{MPa}$ was imposed at $\mathrm{t}=22 \mathrm{hr}$ and this stress was maintained constantly until the stress level was raised to $8.5 \mathrm{MPa}$ at $\mathrm{t}=90 \mathrm{hr}$. Moreover, a small amount of deformation at constant stress was observed during this period (Fig. 26). The increased deformation in Sequence \#3 at stresses above $4.0 \mathrm{MPa}$ can be attributed to the closing of horizontal cracks and vugs in the sample. Figure 25 also shows that horizontal displacement along one surface increased dramatically at stresses above $5 \mathrm{MPa}$. Vertical fractures in the region spanned by the displacement transducer were observed to have opened and apparently caused the expansion. In addition, the stress cycles imposed at $t=90$ and $t=98$ yield values for Young's modulus between 15 and $20 \mathrm{GPa}$, which are somewhat higher than values observed for Sequences \#1 and \#2.

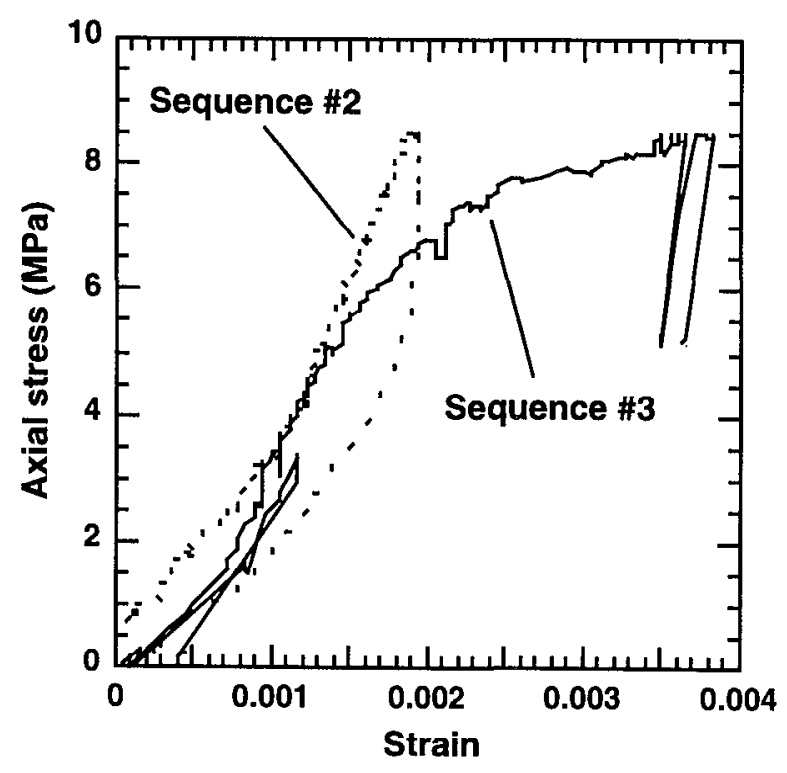

Fig. 25. Stress-strain curve for portion of Sequence \#3 conducted at ambient temperature. The stress-strain curve for Sequence \#2 is shown for reference. 


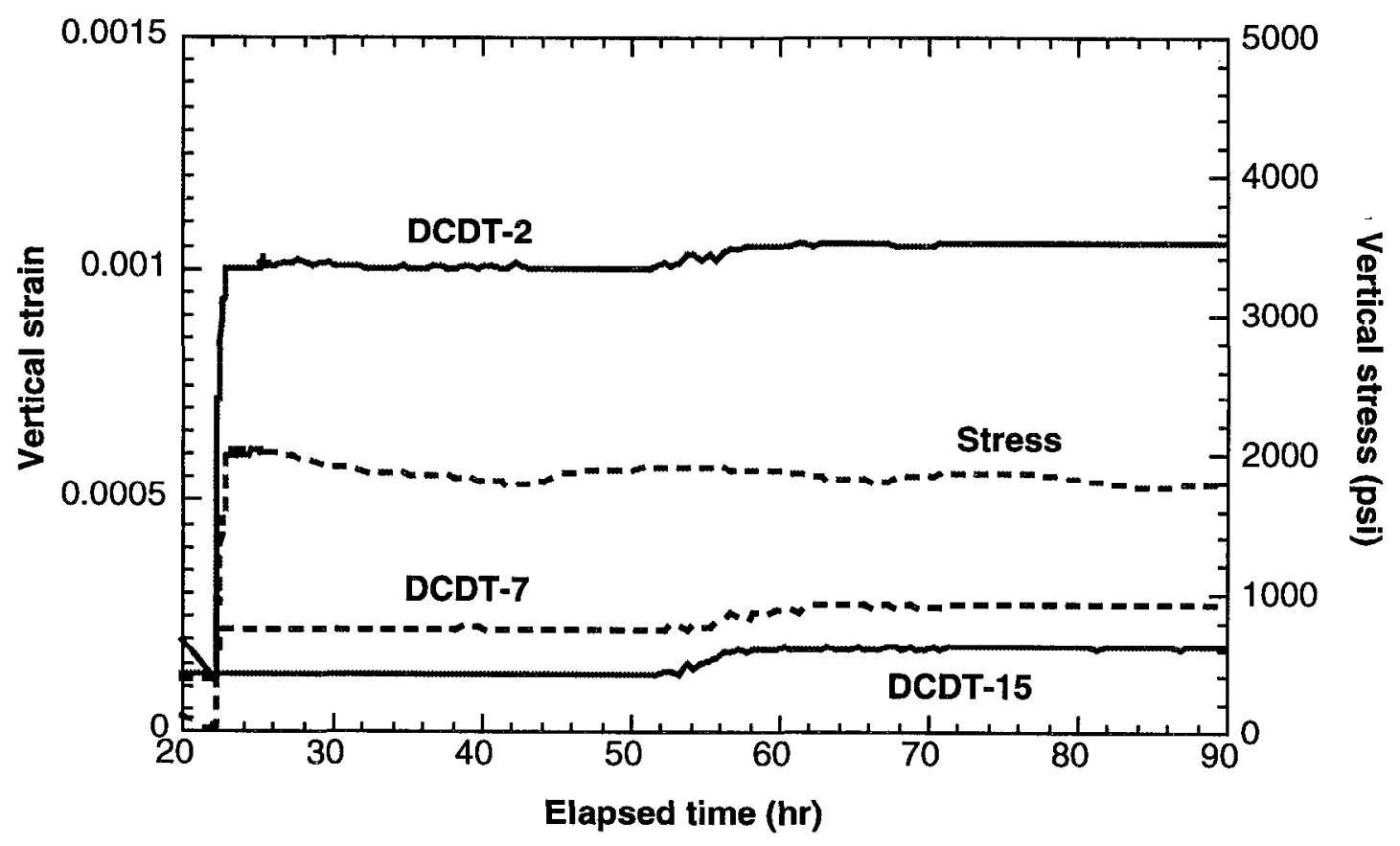

Fig. 26. Time-dependent deformation shown on three displacement transducers during constant load at ambient temperature.

Finally, it is important to note that during Sequences \#2d and \#2e, noticeable spalling occurred at several locations on the block. This was not observed during any of the cycles in Sequence \#1 nor in Sequences \#2(a-c) and indicates that subcritical crack growth occurs even at very low stresses in this rock when it is subject to cyclic loading. This may be relevant for evaluating the effect of seismic shaking of the potential repository over long times and at elevated temperature and humidity, because the velocity of subcritical crack growth is known to increase as temperature and humidity are increased. 


\subsection{Testing at Elevated Temperature}

The sample was also tested at elevated temperature as shown in Table 3. The temperature and stress history for Sequence \#3 are shown in Fig. 20. This figure shows that the vertical stress was cycled between approximately 5 and $8.5 \mathrm{MPa}$ while the sample was held at temperatures of approximately 50 and $85^{\circ} \mathrm{C}$ for a period of 2 months. This section presents a discussion of the temperature distribution in the block at different times during the test, and data for the deformation of the block at temperatures of approximately 50 and $85^{\circ} \mathrm{C}$. Temperatures were monitored continuously at the 12 locations described in Section 3.3 (see Figs. 10 and 11).

\subsubsection{Temperature Distribution}

In this section the temperature distribution in sample SB-1 over time is discussed and analyzed. The purpose of the section is to evaluate the experimental method used to control temperature, and to describe the temperature distribution at particular times when velocity and deformation measurements were made. The intent of the test was to measure deformation and velocity at temperatures of 23,50 , and $85^{\circ} \mathrm{C}$. The general temperature history imposed on the sample is shown in Fig. 27. This figure presents data from thermocouples T1-T5 located along the vertical midplane of the sample (see Fig. 10), and shows that the general signal quality from the thermocouples was quite high. The signal quality from the horizontal thermocouples was similar, and is not shown here. This figure also shows that heating started at about 250 hours after the start of Sequence 3 and the temperature was raised to $50^{\circ} \mathrm{C}$. The heating rate was approximately $1^{\circ} \mathrm{C} / \mathrm{hr}$, and at approximately $280 \mathrm{hr}$ the power was reduced in order to maintain temperature at $50^{\circ} \mathrm{C}$; the fluctuations between 285 and $400 \mathrm{hr}$ were caused by changes in heater power introduced to gain an understanding of the thermal response of the system and to find the proper power level for maintaining sample temperature at $50^{\circ} \mathrm{C}$. 


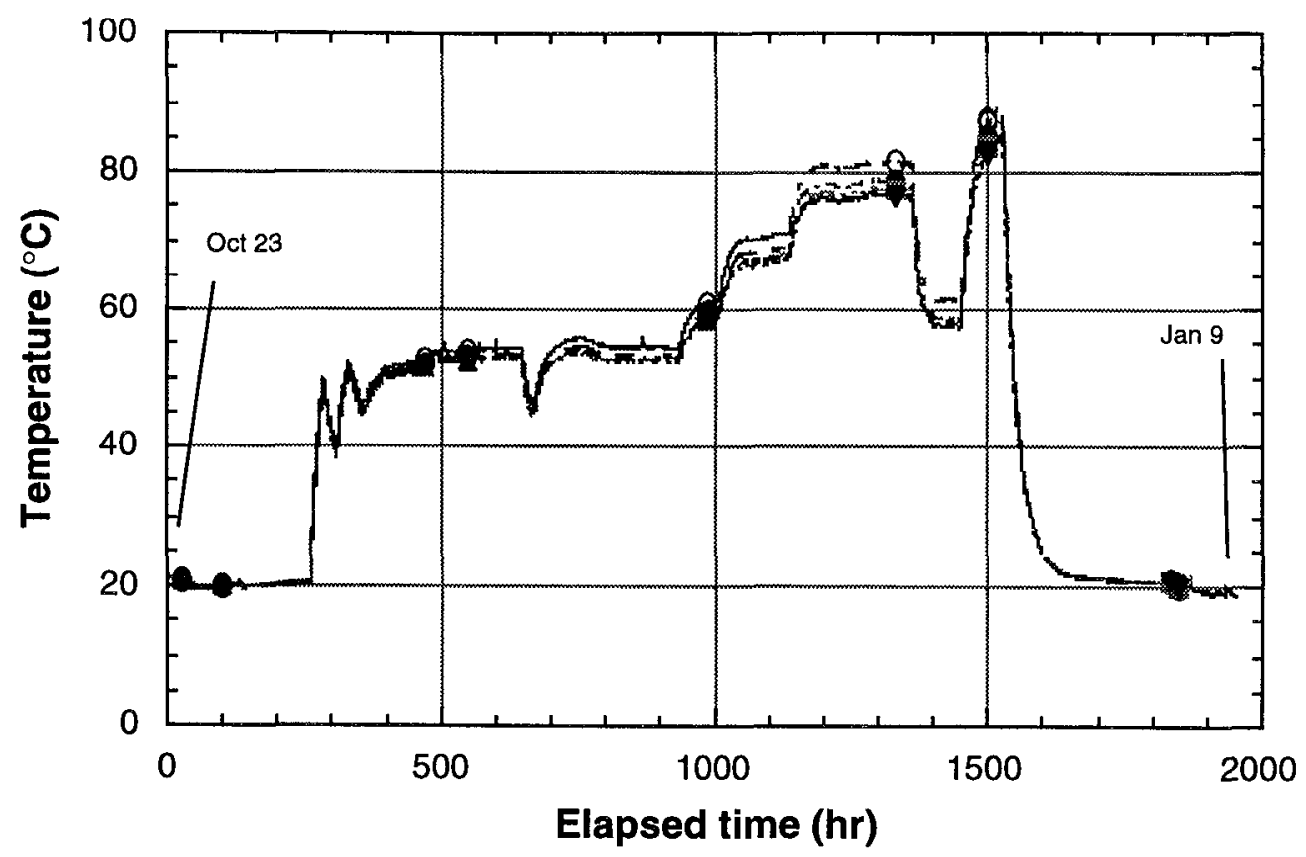

Fig. 27. Temperature history of Sequence \#3 measured using vertical thermocouples (T1-T5).

The temperature stabilized at about $400 \mathrm{hr}$ and was held at $50^{\circ} \mathrm{C}$ until $\sim 920 \mathrm{hr}$. Two sets of velocity measurements were made and one stress cycle was imposed on the sample during this period. The temperature distribution through a vertical midplane of the sample at $500 \mathrm{hr}$ is shown in Fig. 28. This figure shows that most of the sample is in the temperature range $50-54^{\circ} \mathrm{C}$, with the center of the top surface the hottest and the bottom corners the coolest. The figure also shows that the temperatures are somewhat symmetric about the vertical centerline of the sample. However, the temperatures were slightly higher on the right side of the figure, which corresponds to the north half of the sample. This figure represents the temperature distribution during a pressure cycle, and the deformation data are discussed in Section 4.2.2. Temperature distribution at $640 \mathrm{hr}$ is very similar to that shown in Fig. 27 and is discussed in Section 5 of this report. The dip in temperature starting at $\sim 650 \mathrm{hr}$ is associated with a set of velocity measurements. As discussed in Section 5 , insulation on the sides of the sample was removed to facilitate measurement of velocity, and this caused about an $8^{\circ} \mathrm{C}$ drop in the temperature. 

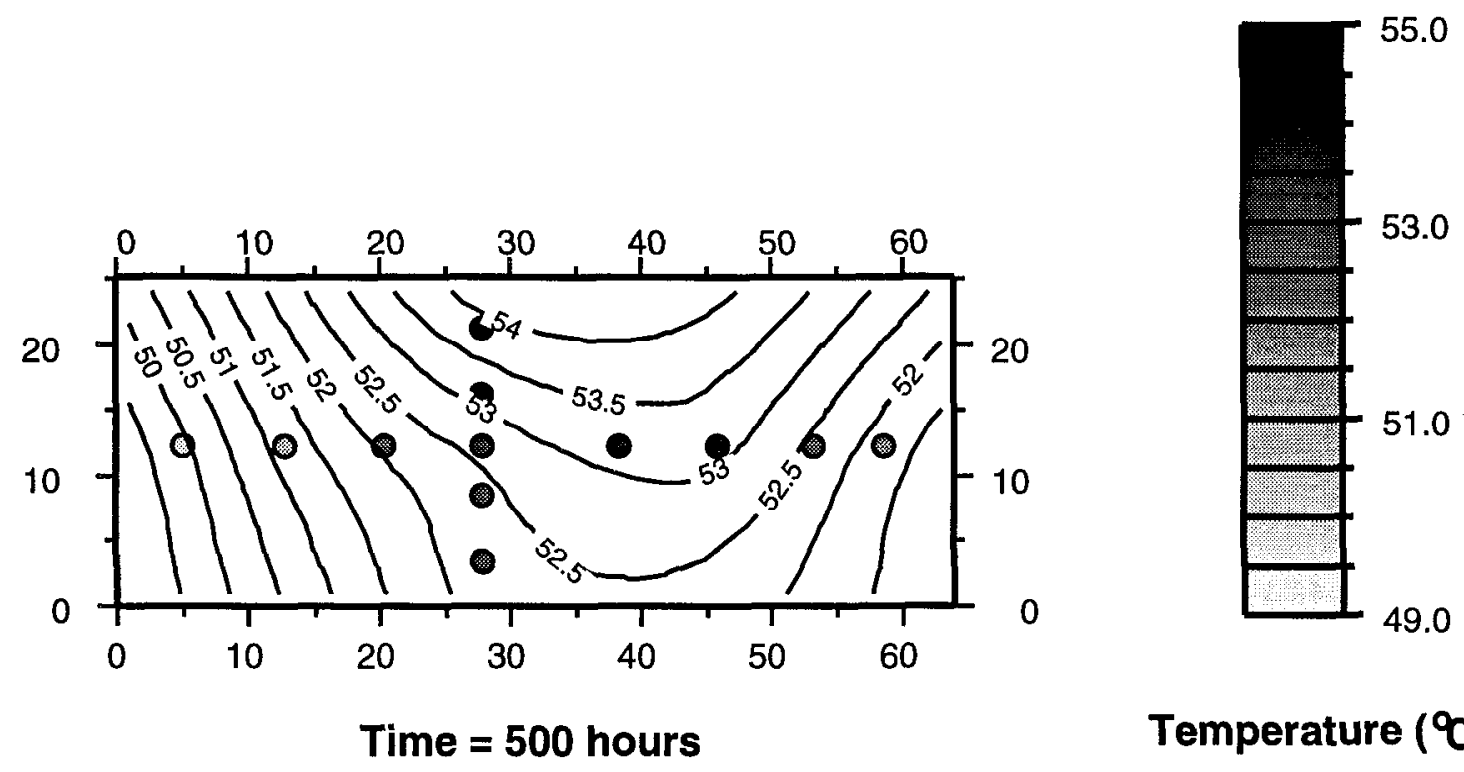

Temperature $\left({ }^{Q}\right)$

Fig. 28. Estimated temperature contours in SB-1 at $t=500 \mathrm{hr}$.

At about $900 \mathrm{hr}$ the first of three increases in power was introduced, with the purpose of raising the temperature of the block to $\sim 90^{\circ} \mathrm{C}$ in a series of steps. The temperature distribution at $1100 \mathrm{hr}$ is shown in Fig. 29. This figure shows that most of the sample was in the temperature range $65-70^{\circ} \mathrm{C}$, with isotherms more horizontal than previously observed. The temperature distribution is also more symmetric about a vertical midplane. The top central part of the sample is still the hottest and the bottom corners are still the coolest parts of the sample, but overall this is quite an even temperature distribution.

Figure 27 shows that the temperature in the block reached nearly $80^{\circ} \mathrm{C}$ at $\sim 1160 \mathrm{hr}$, after which temperature was held constant for nearly $200 \mathrm{hr}$. Figure 30 shows the temperature distribution at $1360 \mathrm{hr}$. This plot shows that once again the sample is the hottest at the top center and coolest at the bottom corners, ranging from 73 to $82^{\circ} \mathrm{C}$, but most of the block is between 75 and $80^{\circ} \mathrm{C}$ and the isotherms are subhorizontal and generally symmetric about the vertical midplane of the sample. The temperature drop after hr 1360 is associated with velocity measurements discussed in Section 5. 

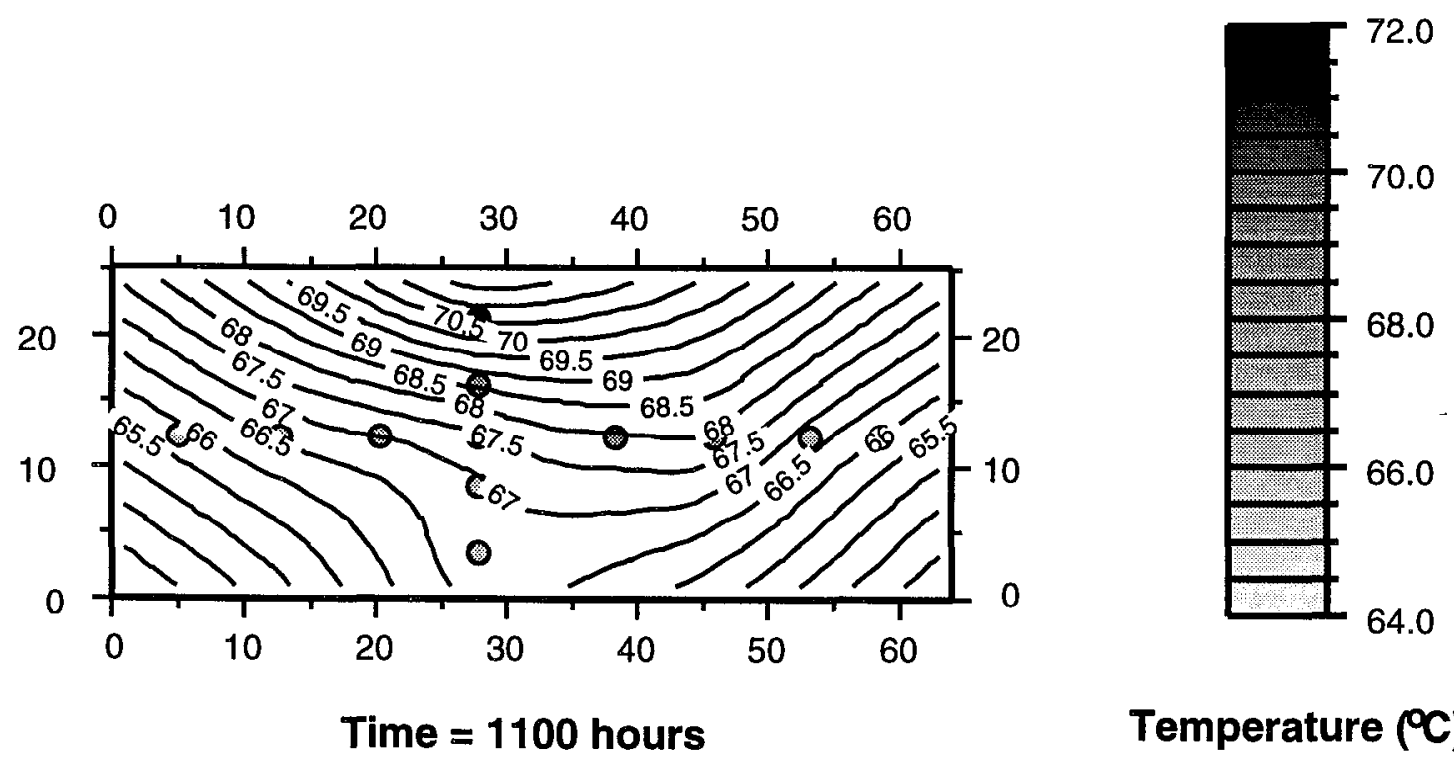

Temperature $\left.{ }^{\circ} \mathrm{C}\right)$

Fig. 29. Estimated temperature contours in SB-1 at $\mathbf{t}=\mathbf{1 1 0 0} \mathrm{hr}$.
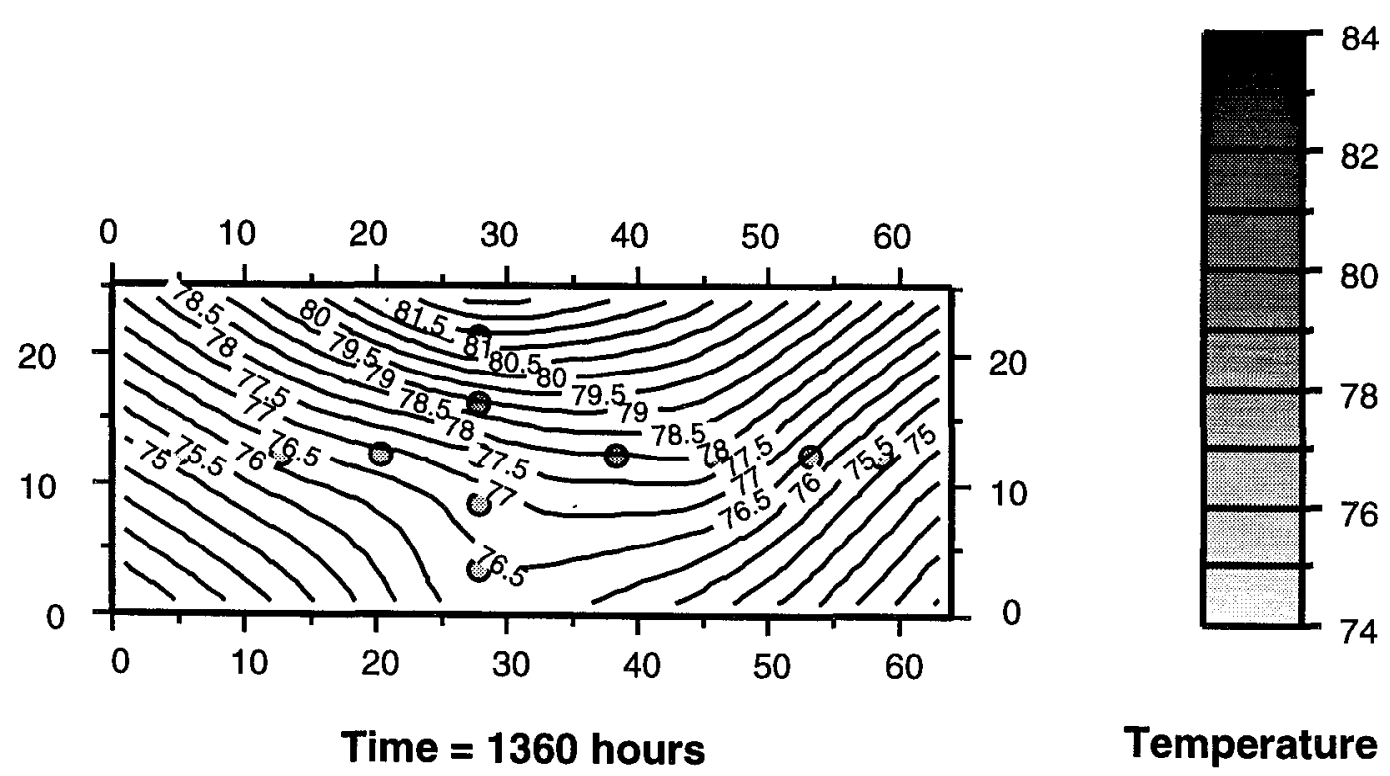

Temperature $\left({ }^{\circ}\right)$

Fig. 30. Estimated temperature contours in SB-1 at $\mathbf{t}=1360 \mathrm{hr}$. 


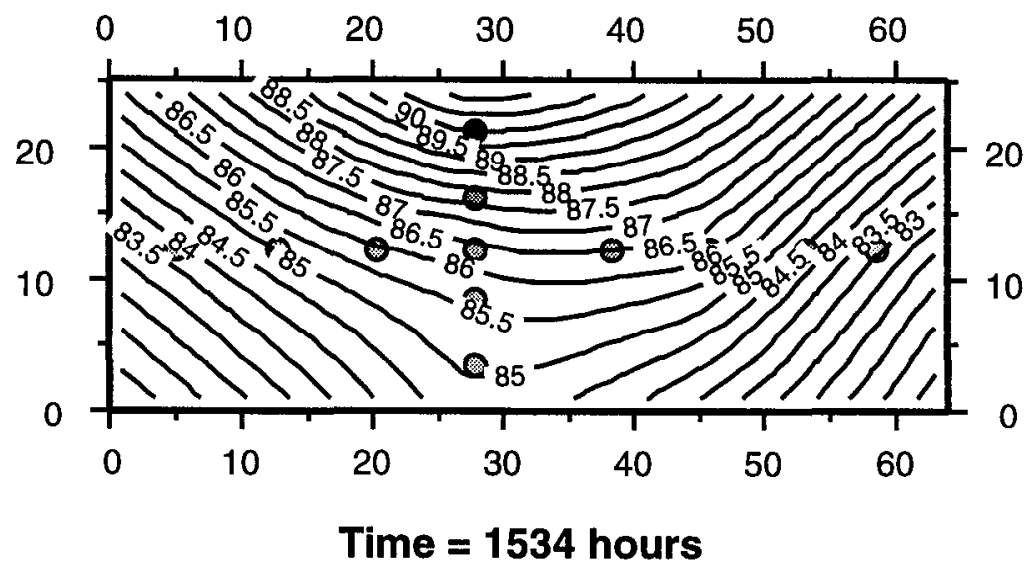

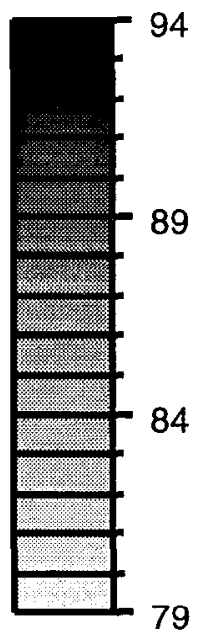

Temperature $\left.{ }^{\circ} \mathrm{C}\right)$

Fig. 31. Estimated temperature contours in SB-1 at $t=1534 \mathrm{hr}$.

Finally, the power was increased slightly and the insulation was repacked and temperatures of about $85^{\circ} \mathrm{C}$ were obtained. The temperature distribution at $1534 \mathrm{hr}$ is shown in Fig. 31. The pattern of temperatures at this time is similar to those at other times, with subhorizontal isotherms, but the range is between $91^{\circ} \mathrm{C}$ at the top center and $81^{\circ} \mathrm{C}$ at the bottom corners of the sample. This figure represents the temperature distribution during a pressure cycle.

\subsubsection{Deformation at Elevated Temperature}

Axial stress on the sample was cycled between 5 and $8.5 \mathrm{MPa}$ twice while the sample was at elevated temperature. The first cycle was performed at a temperature of $50^{\circ} \mathrm{C}$ at about $500 \mathrm{hr}$, while the second cycle was performed at a temperature of $85^{\circ} \mathrm{C}$ at $1540 \mathrm{hr}$. Finally, the stress was cycled again when the temperature had reached room temperature.

Stress-strain data for the three temperatures are shown in Fig. 32. This figure includes the stress-strain data for the ambient-temperature phase of this loading sequence (\#3). This figure shows the following features:

(1) The stress-strain curves for 50 and $90^{\circ} \mathrm{C}$ are offset from the curve for $23^{\circ} \mathrm{C}$, indicating that deformation occurred at constant stress while the sample was heated to temperature and held at temperature. 


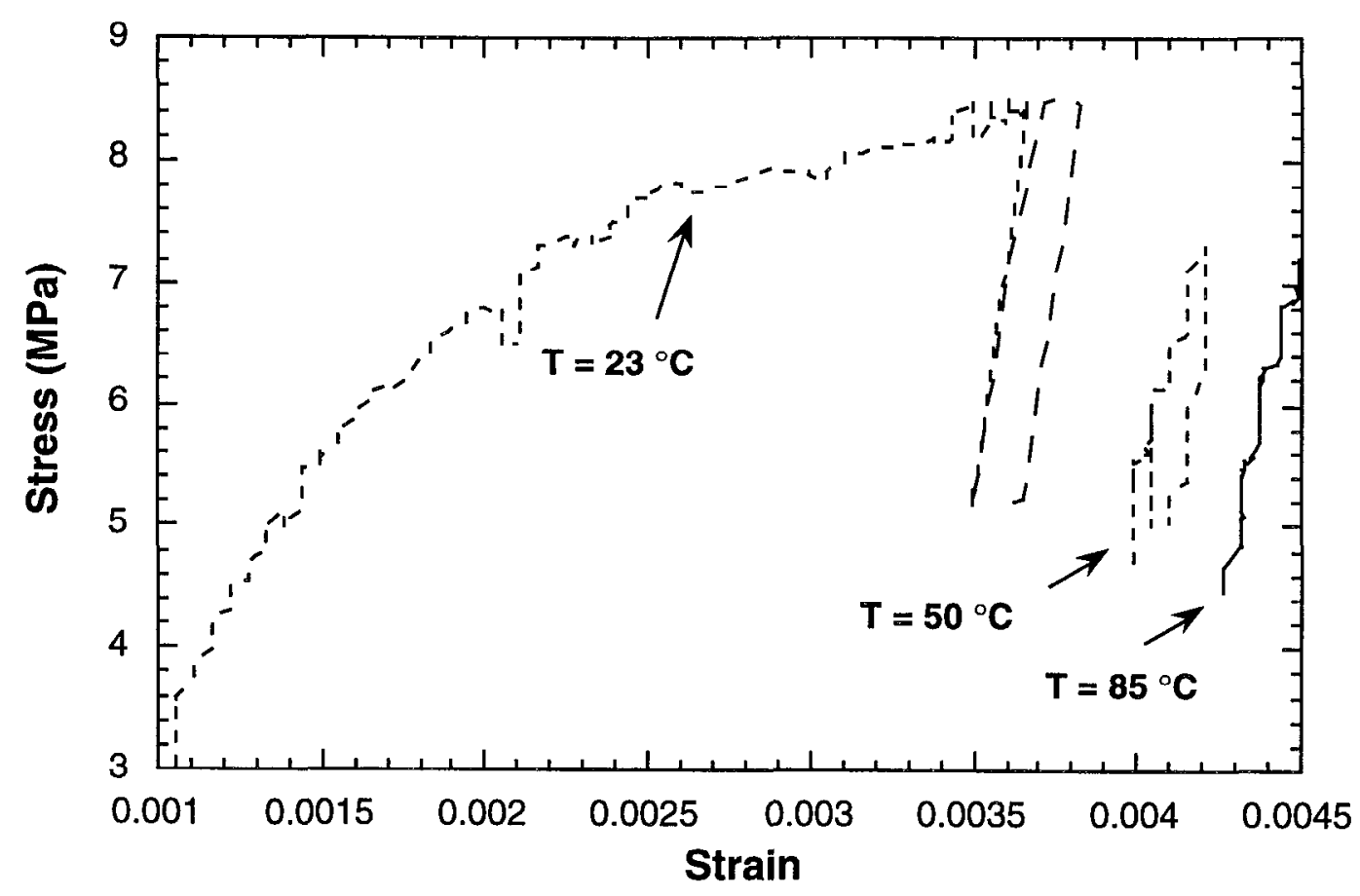

Fig. 32. Stress-strain behavior at elevated temperature. Behavior at $\mathbf{T}=23^{\circ} \mathrm{C}$ is shown for reference.

(2) The modulus decreases as temperature is increased.

(3) The stress-strain curves at elevated temperature exhibit a stepwise behavior.

Detailed examination of data from the transducers measuring the complete height of the block indicates that the loading/unloading modulus decreased from $19 \mathrm{GPa}$ for the unheated case to $10 \mathrm{GPa}$ for the rock at $85^{\circ} \mathrm{C}$. This is a reduction of nearly a factor of two. Data for transducers that monitored matrix material indicate that increasing the temperature reduced the matrix modulus from $54 \mathrm{GPa}$ to $32 \mathrm{GPa}$; again, this reduction is nearly a factor of two. One other observation is that at the higher temperatures, the matrix appears to contribute more to the deformation than it does at the lower temperatures.

Stress-strain data for unloading from 8.5 MPa after the sample had cooled down are shown in Fig. 33. This figure shows that significant deformation remained in the sample after is was cooled from 85 to $23^{\circ} \mathrm{C}$. The observed unloading modulus of $11 \mathrm{GPa}$ is similar to that observed in the heated rock. It is important to note that the permanent strain of $\sim 0.0034$ shown in this figure after cool-down and unloading was verified by comparing measurements of the block 
dimensions from before and after the test. Moreover, measurements on the block also show that it grew shorter, and broader with lateral expansion of the block. The lateral expansion is somewhat misleading, however, because a significant amount of near-surface slabbing occurred on the vertical faces during the test.

This is a preliminary report and more data reduction needs to be done on the deformation data; also, results from this series of measurements need to be compared with results from future tests on small blocks, in order to refine the interpretation.

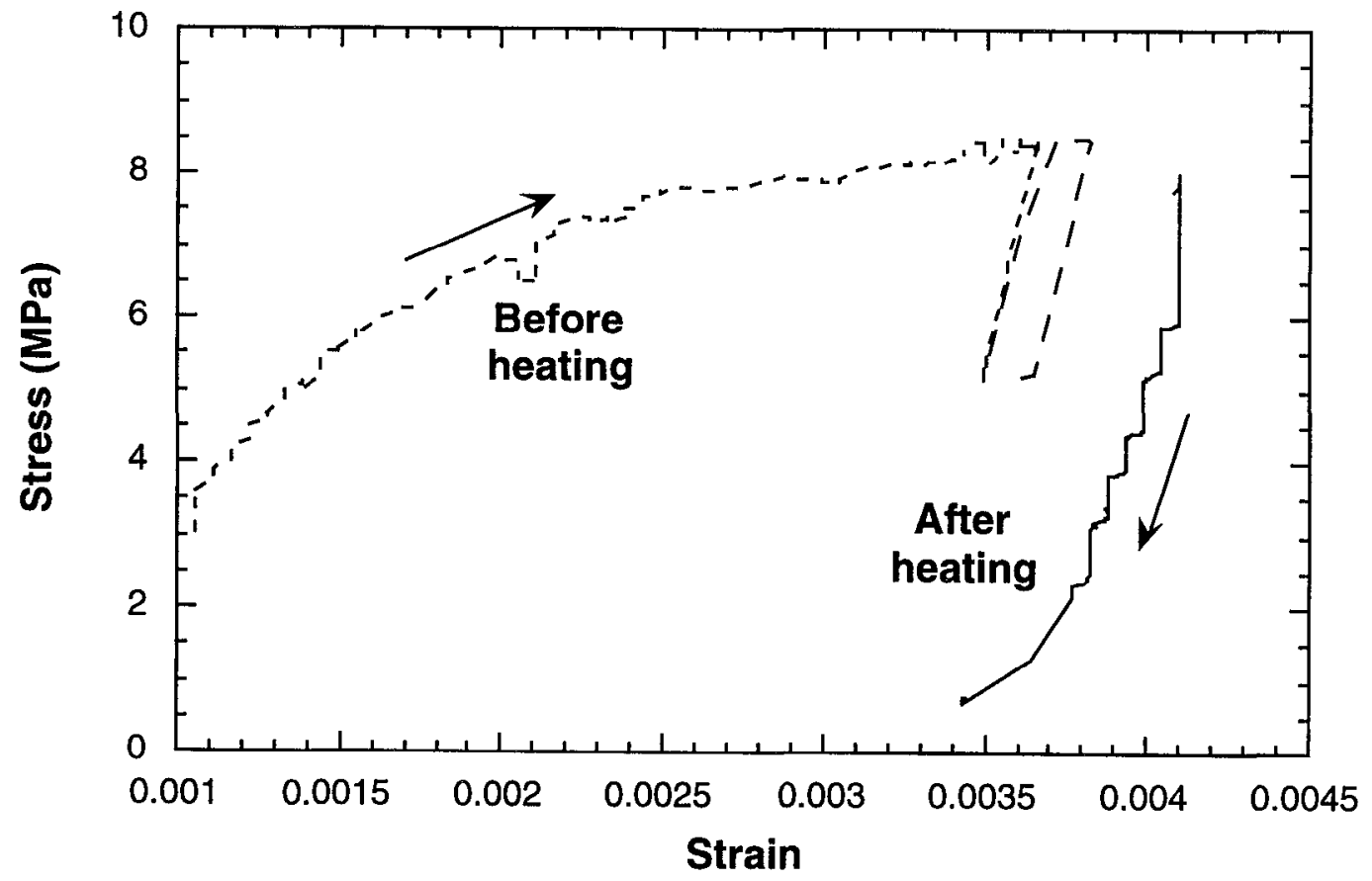

Fig. 33. Stress-strain behavior before heating and at cool-down. 


\subsection{Results-Velocity Measurements}

This section describes results of elastic-wave velocity measurements made as part of the laboratory tests on small block samples of Topopah Spring tuff. The purposes of the velocity measurements include determining how the elastic properties of the rock vary with temperature and applied stress; quantifying the anisotropy if these properties differ in the vertical and horizontal directions (perpendicular and parallel to the fabric of the welded tuff); measuring the effects of heterogeneities such as vugs, inclusions, and fractures; detecting evidence of mechanical damage such as velocity reduction during microcrack formation; comparing dynamic moduli from velocity measurements with static moduli from concurrent displacement measurements; and recording acoustic emissions that may occur during phase transformations of silicon dioxide polymorphs in blocks heated above $200^{\circ} \mathrm{C}$. Elastic-wave velocities are measured using the pulse transmission technique, in which a signal from a pulse generator is transmitted into a rock by using a transducer polarized for compressional or shear waves. The elastic wave travels through the rock and is detected by a similar ultrasonic transducer. The transducers communicate with a data acquisition system that triggers the source pulse and displays the transmitted signal as a function of time. The time series is examined to determine transit time through the rock. Wave velocities are calculated using the transit time and the distance between the paired transducers. Dynamic moduli are computed from the velocities using the density of the rock. This report focuses on results of compressional wave velocity measurements conducted on an unheated block prior to uniaxial loading, as well as measurements made at elevated stress and temperature conditions in that block. Shear-wave measurements, acoustic emissions, and measurements made in other small blocks will be the subjects of future work.

Measurements on the small tuff sample discussed in Section 3.5 showed that velocities could be determined accurately for compressional waves traveling many tens of centimeters through tuff only if good coupling could be achieved for the transducers. The measured velocity parallel to the foliation in this small tuff sample was approximately $4.6 \pm 0.2 \mathrm{~mm} / \mu \mathrm{s}$, and the compressional-wave velocity perpendicular to the foliation was about $4.3 \pm 0.1 \mathrm{~mm} / \mu \mathrm{s}$. This suggests that the Topopah Spring tuff may be slightly anisotropic, with velocity anisotropy of up to $7 \%$. Although the difference in velocities measured in two directions is larger than the measurement uncertainty, this difference could be caused by heterogeneity 
rather than anisotropy. Too few measurements were performed on this one sample to establish the presence of anisotropy, but these measurements do show that the possibility of anisotropy must not be ignored when measuring the properties of Topopah Spring tuff. (A velocity anisotropy may indicate anisotropy in other rock properties, such as permeability, since the velocity anisotropy is related to the rock fabric. Velocity anisotropy of more than a few percent is not a negligible amount. Although it is not possible to predict the amount of anisotropy for other physical properties by using the velocity anisotropy, the presence of anisotropy in the velocity results indicates that other physical properties should be measured as a function of direction when data are collected.) These preliminary measurements on the small piece of tuff were used to determine how the velocity measurement system should be configured to record useful data for distances of tens of centimeters in tuff samples, and to explore how anisotropy and heterogeneity of the samples may affect the results. This information provided the basis for the apparatus configuration used to measure compressional-wave velocities in a small block of tuff, sample SB-1.

For measurements made through the shorter horizontal dimension of the block, the path length was $322 \pm 2 \mathrm{~mm}$. Source and receiver coordinates were determined to within $\pm 3 \mathrm{~mm}$. Initial measurements used $100 \mu$ s for the long record used to identify the approximate arrival time, typically found near $75 \mu \mathrm{s}$. Between 3000 and 10,000 traces were stacked for each measurement in order to achieve a signal-to-noise ratio of at least 2:1. The noise level was typically $3-5 \mathrm{mV}$, and signals were usually about 5-15 mV. Once an approximate arrival was identified, a trigger delay of about $70 \mu$ s and a record length of $10 \mu$ s were used to magnify the display of the time series in the region of the compressional-wave arrival. Arrivals were determined to within $0.4 \mu \mathrm{s}$ for most of the measurements. Frequencies were typically below $200 \mathrm{kHz}$.

After the arrival was measured from the $10-\mu$ s record, the system delay (determined using aluminum calibration samples) was subtracted from the arrival time to get the actual travel time. Then for each velocity measurement, the path length of $322 \mathrm{~mm}$ was divided by the travel time to obtain the velocity in $\mathrm{mm} / \mu \mathrm{s}$.

The first set of velocity measurements for small block sample SB-1 was made at ambient pressure and temperature conditions, after Sequence \#2 was finished. Results of these velocity measurements through the shorter horizontal dimension of the small block are shown in the top part of Fig. 34. Velocities were found to be near $3.6 \mathrm{~mm} / \mu \mathrm{s}$ in the central region at the base of the block, increasing to about 4.2 

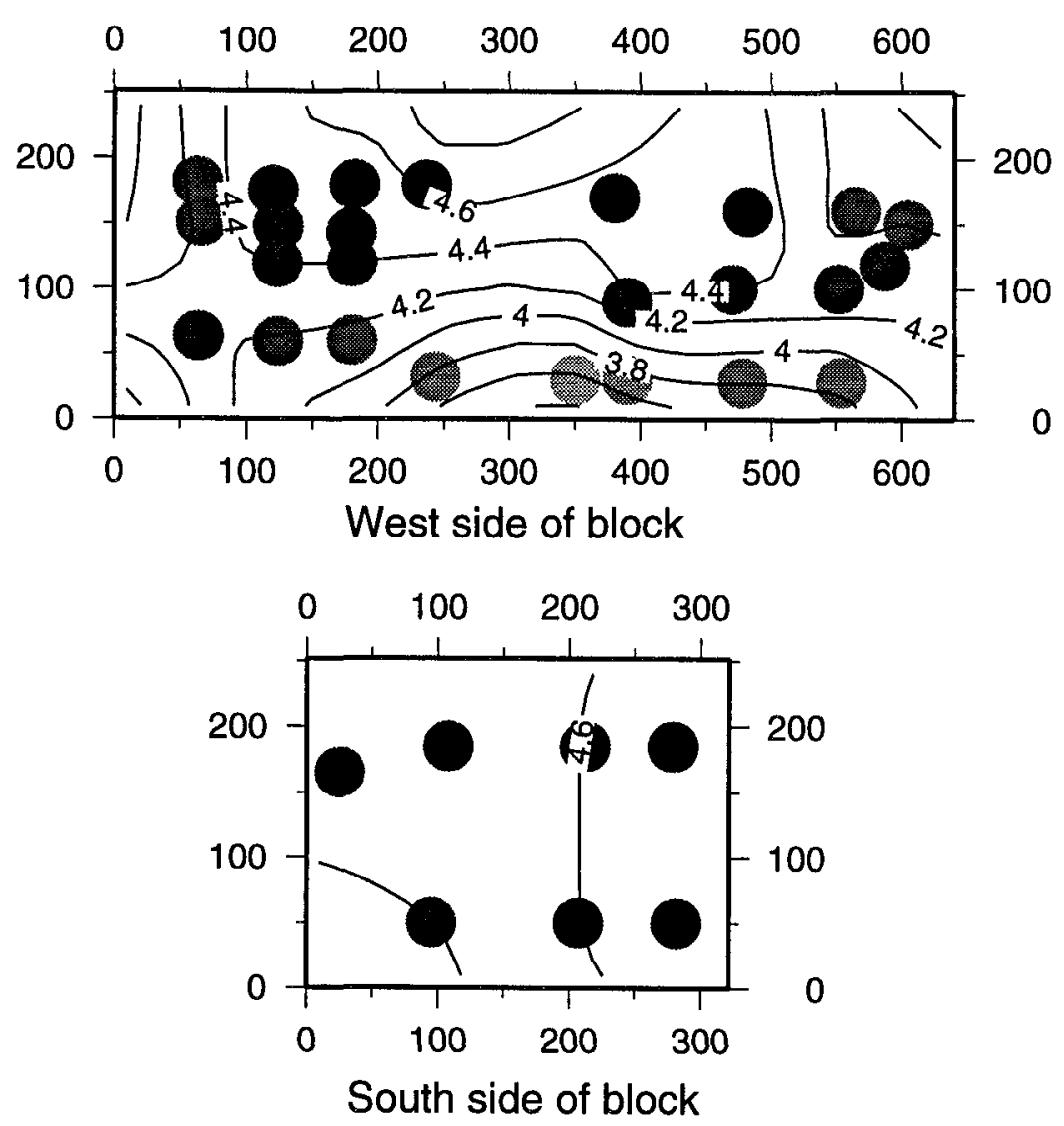

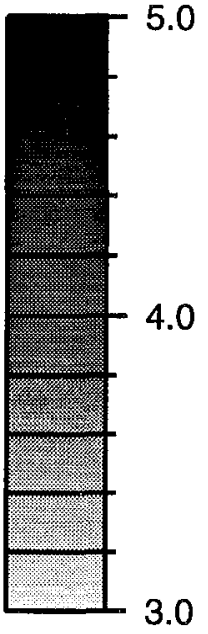

P-wave velocity $(\mathrm{mm} / \mu \mathrm{s})$

Fig. 34. Results of P-wave velocity measurements made after Sequence \#2, at ambient pressure and temperature conditions.

to $4.5 \mathrm{~mm} / \mu \mathrm{s}$ throughout most of the block, and up to $4.7 \mathrm{~mm} / \mu \mathrm{s}$ near the top of the block. These measurements had an uncertainty of about 0.1 to $0.2 \mathrm{~mm} / \mu \mathrm{s}$. Most of the recorded energy had frequencies of $100-200 \mathrm{kHz}$, which implies that the wavelengths for these velocity measurements were about $2-5 \mathrm{~cm}$. The dots in Fig. 34 are about a wavelength wide, showing that this number of velocity measurements provided excellent coverage over most of the small block. Measurements made within one wavelength of each other yielded identical velocities, as expected. The low velocities found near the base of the small block correspond to a zone having many large, cracked vugs.

Similar velocity measurements were made through the longer horizontal dimension of the small block, with path lengths of $640 \pm 2 \mathrm{~mm}$. For these measurements, the long time record was $200 \mu$ s and arrival times were determined precisely by using short records of about $20 \mu \mathrm{s}$. Arrivals were typically near $140 \mu \mathrm{s}$, 
and a trigger delay of about $135 \mu$ s was used. For most measurements, 3000 traces were stacked, to achieve a signal-to-noise ratio of about 2.5:1. The noise level was typically about $3 \mathrm{mV}$, whereas the signal level was about $8 \mathrm{mV}$ for the stacked data. This low signal level resulted from the relatively long travel path for measurements made in this direction. Most arrivals were picked to within $\pm 0.8 \mu \mathrm{s}$, representing an uncertainty equivalent to about $0.5 \%$ of the travel time. Results of these velocity measurements are shown in the bottom part of Fig. 34 .

Compressional-wave velocities were $4.4-4.6 \mathrm{~mm} / \mu \mathrm{s}$ for measurements made along the longer horizontal dimension of the small block. These results are much more uniform than the results from the other horizontal direction, possibly because the effects of heterogeneities are less significant over the longer path length. Uncertainties in the velocities are the result of the uncertainty of about $3 \mathrm{~mm}$ in the path length (about $0.5 \%$ uncertainty); the uncertainty in the arrival time, typically $0.8 \mu$ s but sometimes up to $2 \mu$ s ( 0.5 to $2.5 \%)$; and an additional uncertainty of up to $0.4 \mu \mathrm{s}$ because of coupling inconsistencies in repeated measurements $(<0.5 \%$ uncertainty). The combined uncertainty in the velocity from all these effects is typically about $1.5 \%$ but may be as large as $4 \%$ for emergent arrivals. Thus the uncertainty is less than $\pm 0.1 \mathrm{~mm} / \mu \mathrm{s}$ for most measurements but may be $\pm 0.2 \mathrm{~mm} / \mu \mathrm{s}$ for a few measurements.

The elastic waves measure average properties with a resolution on the order of a wavelength, and cannot detect heterogeneities that are smaller than about $1 / 4$ of a wavelength. The velocity determined in each measurement represents an average over the entire path length through the block. Vugs having sizes smaller than about $0.5 \mathrm{~cm}$ will not significantly affect velocity measurements, but extensive regions containing many vugs can reduce velocities by as much as $10 \%$, as shown in Fig. 34. The measured velocities in the small block were found to be between 3.6 and $4.7 \mathrm{~mm} / \mu \mathrm{s}$, in agreement with earlier preliminary measurements made on small pieces of tuff and also in agreement with velocity measurements from the Gtunnel test. Heterogeneities such as vugs have a significant effect on the compressional-wave velocities, but the effect is reduced over longer path lengths. It is possible to measure velocities through $0.64 \mathrm{~m}$ of tuff using this laboratory apparatus, and it should be possible to measure velocities for samples up to $1 \mathrm{~m}$ across if good transducer coupling is achieved. The compressional-wave velocities determined at ambient pressure and temperature conditions for this small block sample correspond to a dynamic Young's modulus of about 25 to $42 \mathrm{GPa}$, if a Poisson's ratio of 0.25 and a density of $2300 \mathrm{~kg} / \mathrm{m}^{3}$ are assumed. This is in 
agreement with static Young's modulus measurements determined for core samples, but is higher than static measurements made at this scale (see Section 4.2). The uncertainty in these estimates of Young's modulus is about a factor of two. Velocities were measured several times during Sequence \#3, and the measurements at 3.5 MPa show that the velocities (see Fig. 35) were nearly unchanged throughout the block compared with values found at atmospheric pressure conditions. The only exception was a region near one of the top corners of the block, where the velocity dropped to $3.1 \mathrm{~mm} / \mu \mathrm{s}$ compared with a previous value of about $4.2 \mathrm{~mm} / \mu \mathrm{s}$. This velocity change may represent crack growth in that region.

However, when the compressive stress was raised to $8.5 \mathrm{MPa}$ during loading cycles, all parts of the block showed drastic velocity reductions (see Fig. 36). Velocities were below $3.0 \mathrm{~mm} / \mu \mathrm{s}$ throughout most of the block. Velocities dropped by $50 \%$ in some parts of the block. Since velocity measurement uncertainties are only a few percent, this decrease in velocity is significant. This decrease in velocity in the horizontal direction accompanies the large deformations shown in Fig. 25, and is indicative of opening of vertical cracks in the sample, and several newly opened cracks were observed.
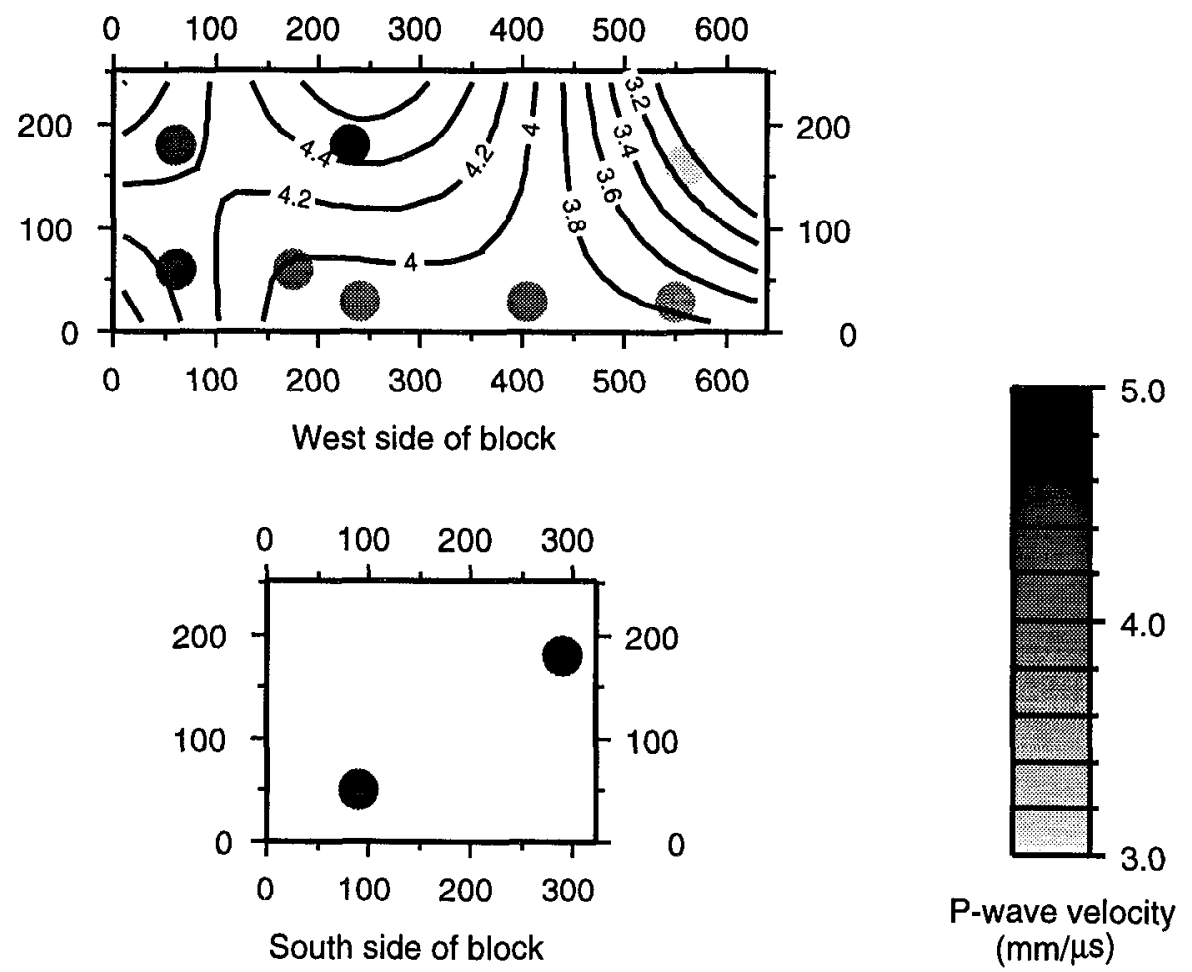

Fig. 35. Results of velocity measurements made during Sequence \#3, at 3.5 $\mathrm{MPa}$ and ambient temperature conditions. 

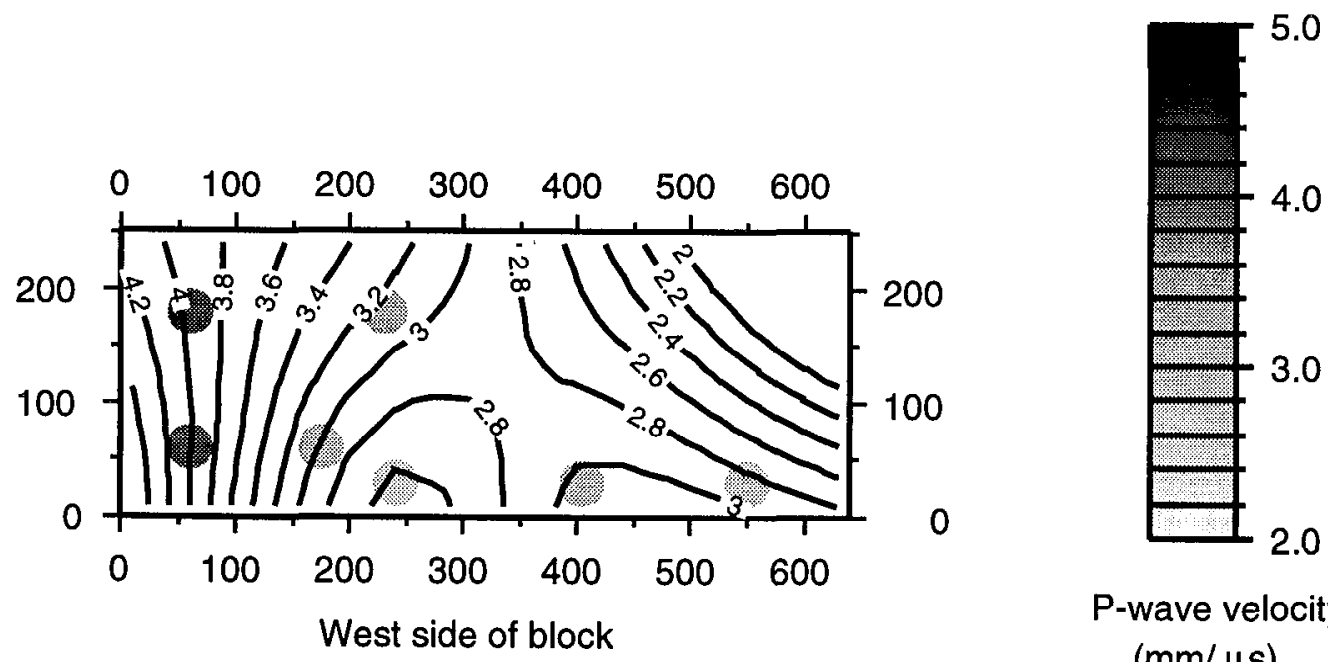

P-wave velocity

$(\mathrm{mm} / \mu \mathrm{s})$

Fig. 36. Velocities measured during Sequence \#3, at 8.5 MPa and ambient temperature conditions.

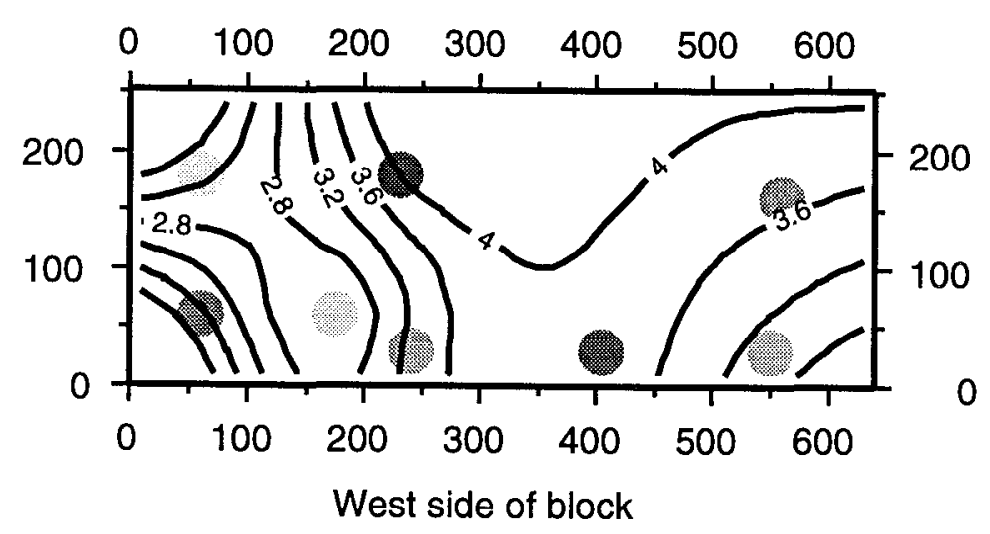

West side of block

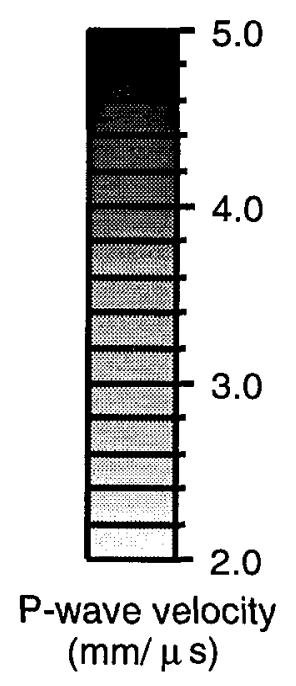

Fig. 37. Velocities measured during Sequence $\# 3$, at $5 \mathrm{MPa}$ and $50^{\circ} \mathrm{C}$.

Velocity measurements were made again during Sequence \#3, when the temperature in the block was raised to about $50^{\circ} \mathrm{C}$ and the applied stress was $\sim 5 \mathrm{MPa}$. Velocities (Fig. 37) increased to about 3.2 to $4 \mathrm{~mm} / \mu$ s in the central part of the block, but dropped to about $2.8 \mathrm{~mm} / \mu \mathrm{s}$ in one end. The temperature increase may have closed some cracks in the central part of the block, but the end of the block having low velocities may have developed some new cracks. The load was cycled up to 
about $7 \mathrm{MPa}$ and returned to $5 \mathrm{MPa}$, and velocity measurements were repeated (Fig. 38). No significant changes in velocity were observed in the central part of the block, but velocities in one end increased dramatically, from $2.8 \mathrm{~mm} / \mu \mathrm{s}$ (Fig. 37) to between 4.2 and $4.5 \mathrm{~mm} / \mu$ s (Fig. 38). These values are close to those originally measured in the unheated, unstressed block (Fig. 34). Cycling the stress at elevated temperature apparently closed some vertical cracks in this part of the block. Further evidence of crack closure was found in the fact that signal-to-noise ratio improved dramatically for long paths $(640 \mathrm{~mm})$ through the block, and it was possible to measure velocities for both horizontal directions through the block (see bottom of Fig. 38).
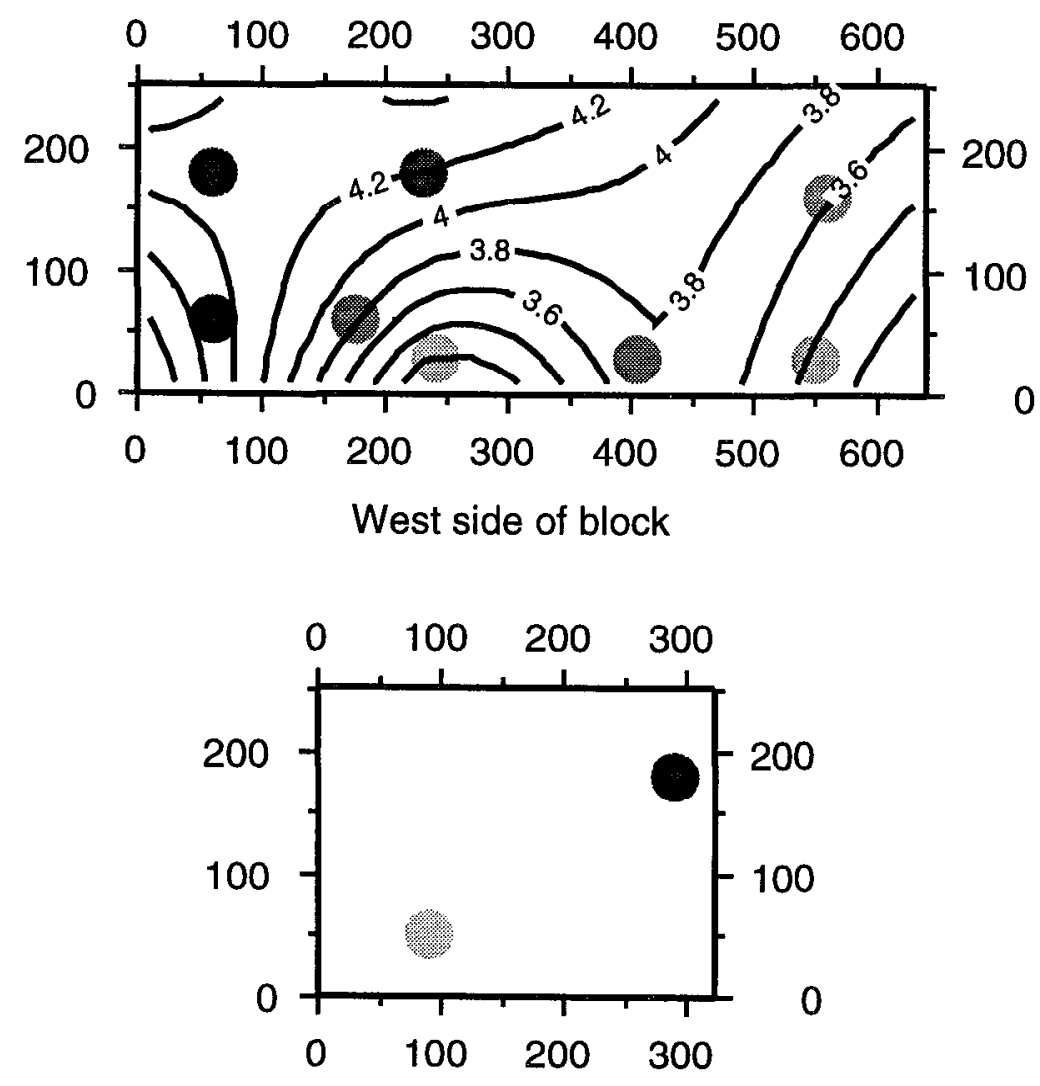

South side of block

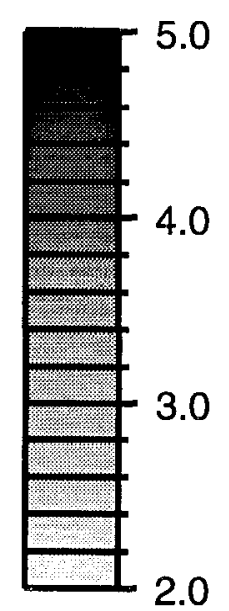

$\mathrm{P}$-wave velocity $(\mathrm{mm} / \mu \mathrm{s})$

Fig. 38. Velocities measured during Sequence \#3, at $5 \mathrm{MPa}$ and $50^{\circ} \mathrm{C}$, after cycling load up to $7 \mathrm{MPa}$. 
Velocities were again measured during Sequence \#3, after the temperature in the block was increased to $80^{\circ} \mathrm{C}$, at an applied stress of 4.5 to $5 \mathrm{MPa}$. Velocities did not change significantly in the lower central portion of the block, but did increase dramatically in the top portion of the block, attaining values over $5 \mathrm{~mm} / \mu \mathrm{s} \mathrm{(Fig.} \mathrm{39).}$ This is even higher than the highest values (about $4.7 \mathrm{~mm} / \mu \mathrm{s}$ ) originally measured in the block (Fig. 34), and indicates crack closure or healing during heating.
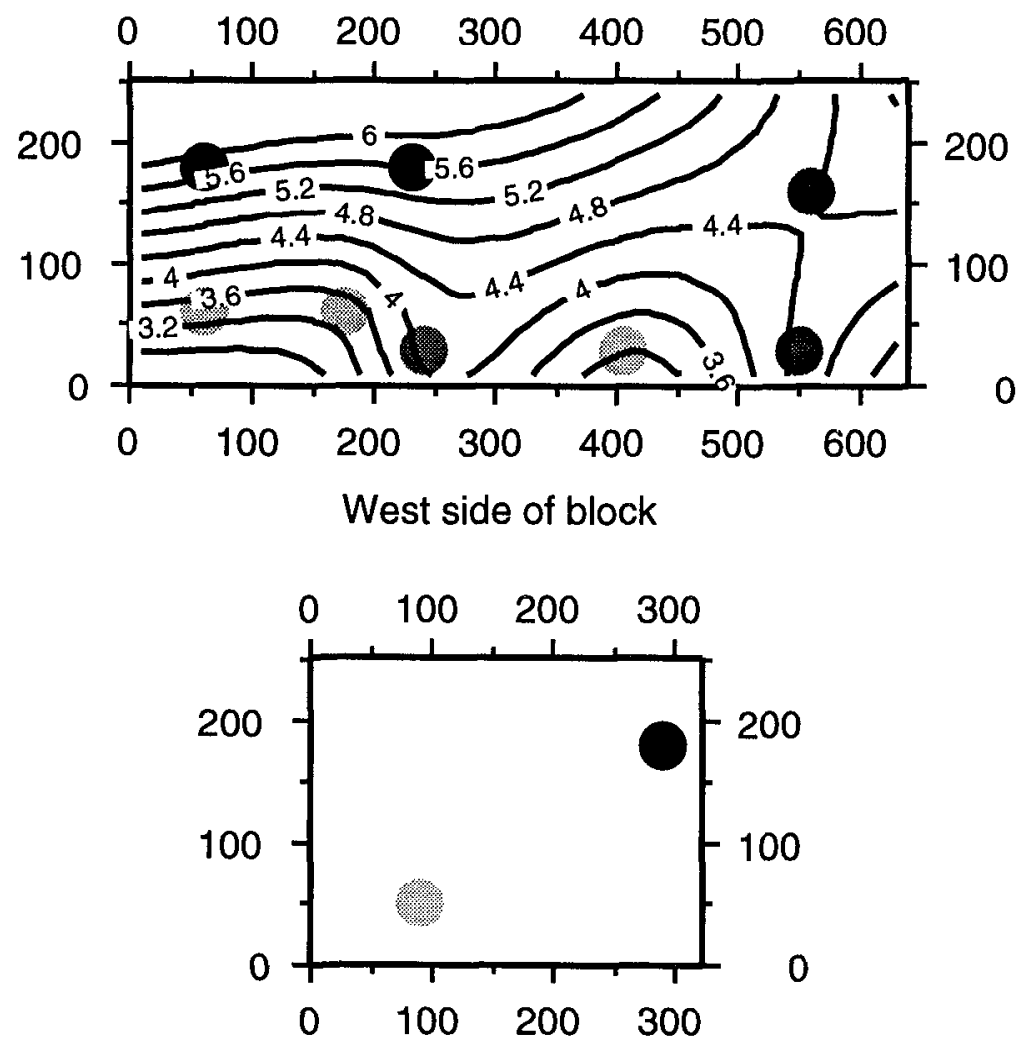

South side of block

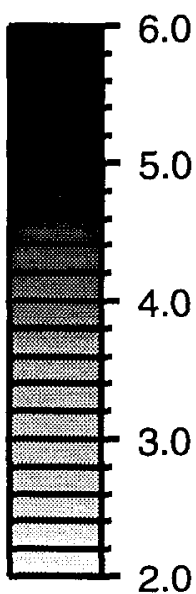

P-wave velocity $(\mathrm{mm} / \mu \mathrm{s})$

Fig. 39. Velocities measured during Sequence \#3, at about $5 \mathrm{MPa}$ and $80^{\circ} \mathrm{C}$. 


\subsection{Comparison of Velocity and Temperature Results}

The velocity results for elevated temperatures (Figs. 37-39) can be compared with contour plots showing the temperature distributions in the block at about the same times.

Figure 40 shows the temperature distribution in the block at about 320 hours. This plot can be compared with Fig. 37, showing velocities at about the same time. The patterns of the velocity and temperature contours are very similar. Regions having higher temperatures also have higher velocities than other parts of the block, and the edges have lower velocities as well as lower temperatures. The highest temperature and velocity values are found in the top center part of the block. The low temperatures at the edges of the block are related to edge effects, in that heat escapes even though there is insulation surrounding the block. The lower velocities at the edges of the block may be due to increased cracking, particularly near the bottom corners of the block. The high velocities are correlated with the high temperatures because the heating does heal some cracks and therefore does raise velocities. Mechanisms of crack healing, such as precipitation of amorphous silica, will be investigated in future tests.

Figure 41 shows the temperature distribution in small block sample SB-1 at 640 hours. This can be compared with the velocity results shown in Fig. 38. Here the contours of the temperatures and velocities do not match as well. There is still a correlation between higher velocities and higher temperatures near the top of the block, and one end of the block shows lower temperatures and lower velocities. However, the high velocities found at the other end of the block are in a lowtemperature region, and the low velocities near the bottom central part of the block in the vuggy zone of Fig. 6 do not have any correspondence to the temperature contours.

Figure 42 shows the temperature distribution at about 1360 hours. This plot can be compared with the velocity results in Fig. 39. The temperature and velocity contours have some similarities. The contours are mainly sub-horizontal throughout the two plots. The highest velocities and temperatures are found near the top of the block, probably because the heat helps to close some of the fractures and raise the velocities. The edge effects are minimal on one end of the block, where velocity and temperature contours match fairly well. The two plots do show some differences, in that the vuggy zone is again visible near the bottom center of the velocity plot, where velocities are low, but does not affect the temperature plot. 
Also, high velocities found at the other end of the block do not correspond to the temperature contours at that end of the block.

In summary, there is a weak but consistent correlation between the velocities and the temperatures, mainly where the high temperatures help to heal cracks and thus are related to high velocities.
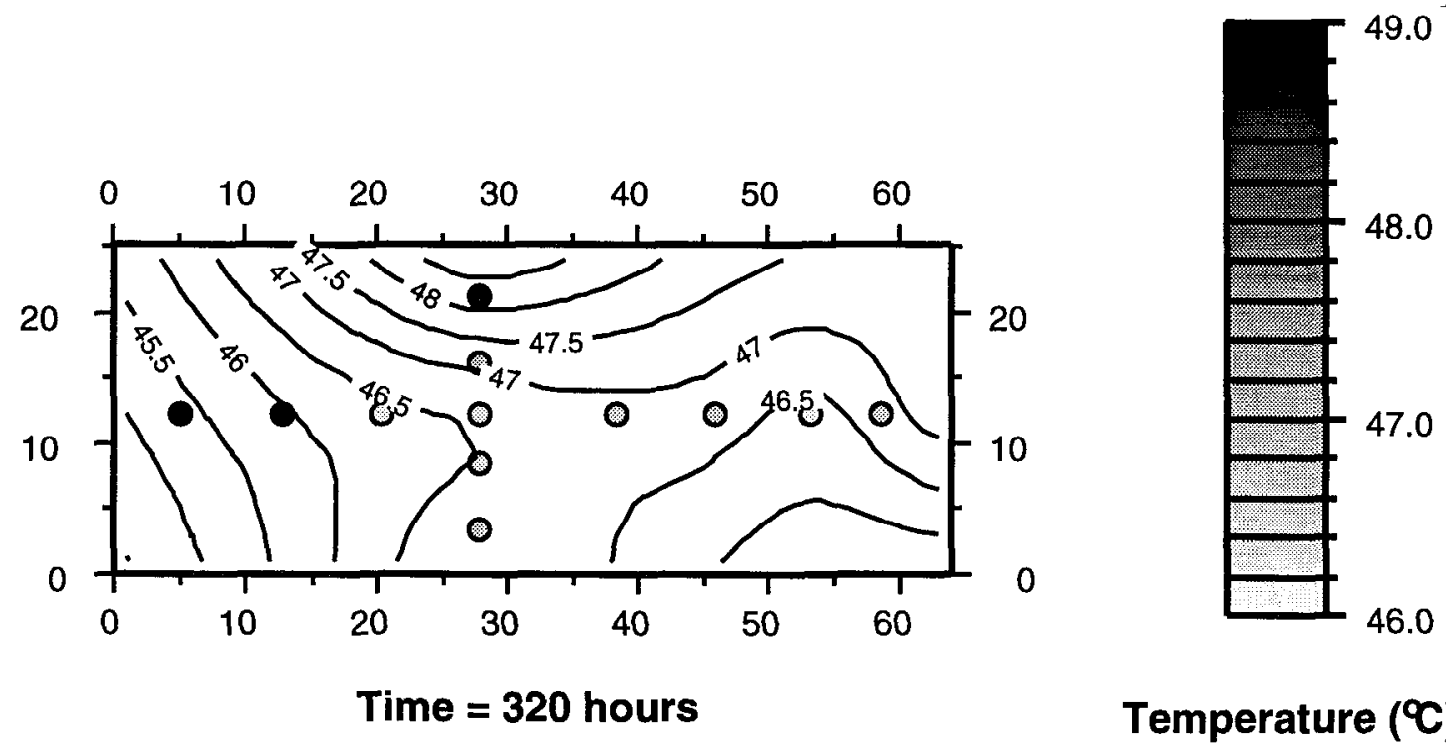

Temperature $\left({ }^{\circ} \mathrm{C}\right)$

Fig. 40. Temperature distribution for small block sample SB-1 at 320 hours.
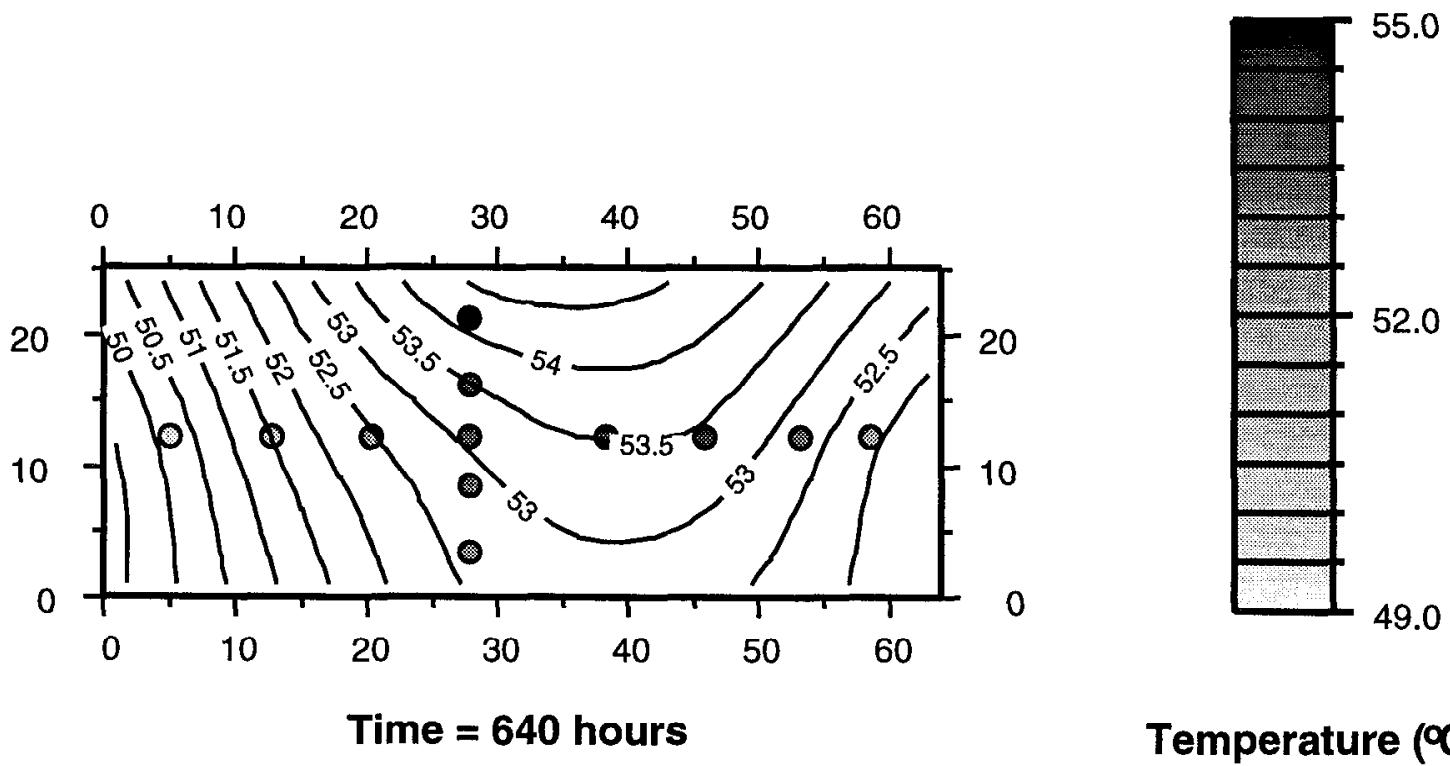

Temperature $\left({ }^{\circ} \mathrm{C}\right)$

Fig. 41. Temperature distribution for small block sample SB-1 at 640 hours. 

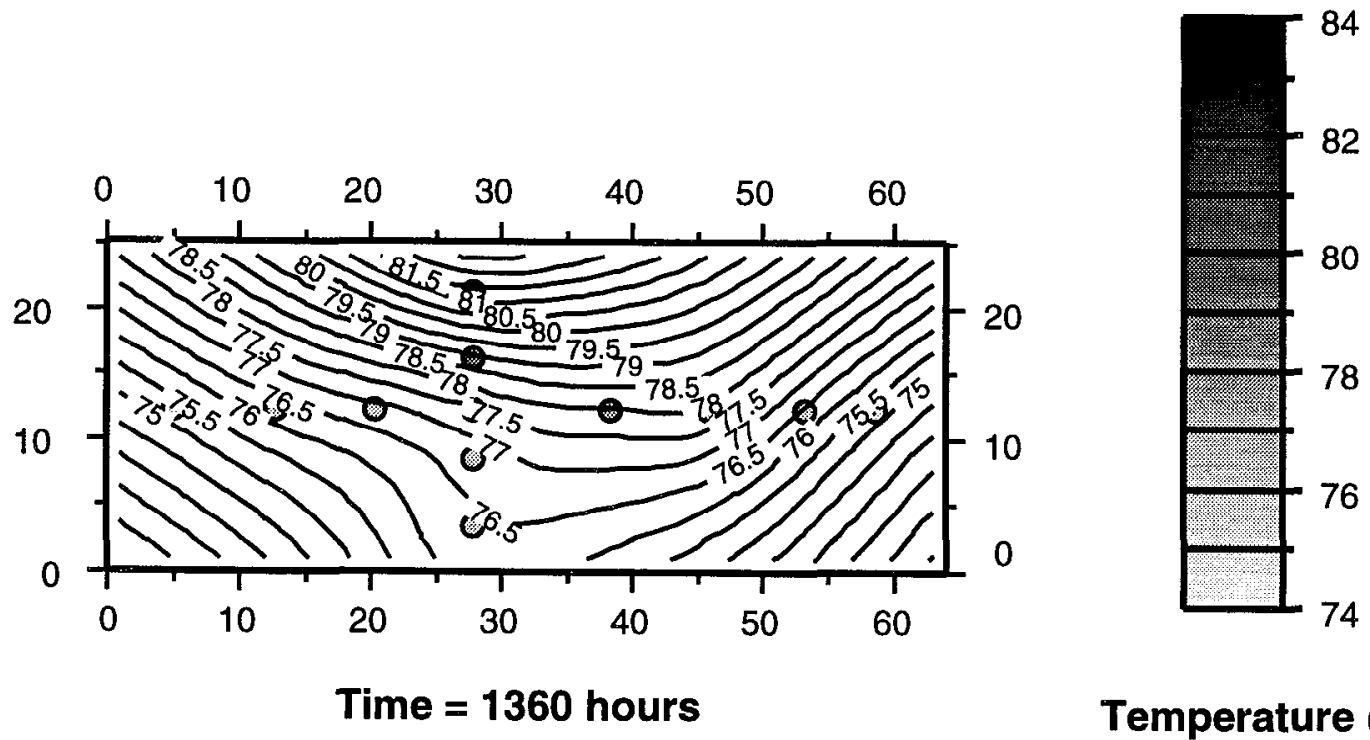

Temperature $\left({ }^{\circ} \mathrm{C}\right)$

Fig. 42. Temperature distribution for small block sample SB-1 at 1360 hours. 


\subsection{Conclusions and Discussion}

In this study a $0.5-\mathrm{m}$-scale block of welded tuff was subjected to a series of 1-day loading tests, and to a long-term thermal-mechanical test in which elevated temperatures and stresses were imposed on the sample for a period of approximately 2 months. Preliminary analysis indicates cycling compressive stress in 1-day tests produced non-linear but repeatable behavior in the 0.5-m-scale block, with most of the deformation occurring across cracks, vugs and fractures. Imposing low levels of compressive stress for periods of a few days caused time-dependent, non-repeatable behavior to occur for cracks oriented both parallel and perpendicular to the applied stress. Under the long-term loading cracks/vugs oriented perpendicular to the applied stress showed significant closure beyond that observed in the 1-day tests. In addition, the long-term loading caused pre-existing hairline cracks oriented in the direction parallel to the applied stress to open, which significantly reduced velocities of waves traveling in this direction. Increasing temperature caused closure of some of the vertical cracks, which increased horizontal velocities. Increasing the temperature also caused a softening of the mechanical response in the direction of loading.

These results have significant implications for the flow and transport properties of the rock in the very near-field region of a repository, as they indicate that some important properties of the rock mass may become increasingly anisotropic with time. For instance, if cracks, vugs, and fractures oriented perpendicular to the maximum principal stress undergo time-dependent closing, permeability in this direction will be reduced and deformation modulus will increase. Moreover, opening of pre-existing hairline cracks that occur near the drift wall and are oriented parallel to it will increase the permeability in this direction, and will change the geochemical environment by exposing different mineral assemblages.

Noticeable spalling occurred at several locations on the block, indicating that subcritical crack growth can occur even at very low stresses in this rock when it is subject to cyclic loading. This may be relevant for evaluating the effect of seismic events on the potential repository over long times. More experiments are needed to provide data on the geomechanical behavior at elevated temperature and humidity. 


\section{Acknowledgments}

Stan Trettenero, Owen Pine, Stephanie Daveler, Stephanie Wood, and John Kelly provided technical support. This work was supported by the Yucca Mountain Site Characterization Project. 


\section{Appendix}

\section{Observations of Fractures in Small Block Samples SB-2 and SB-3}

\section{Observations (SB-2)}

\section{South Face}

There are multiple open fractures and even more closed fractures; however, there are very few vugs. There is a large fracture located near the west face that extends from one end of the face to the other, beginning at the top face and ending at the bottom. Most of it is open, with only a small portion in one or two areas being closed, or having a mineral filling. This fracture is at an angle of about $80^{\circ}$ relative to the bottom face. There is another large fracture more toward the center of the face that extends from the top face to the bottom at about $90^{\circ}$ relative to the bottom face. The top portion of this fracture is closed; however, as you follow it down toward the bottom, it opens up, leaving only small parts closed or filled. There is a third fracture that is located close to the east face and also extends from the top to the bottom. The bottom portion of the fracture is open, and the top part is closed or filled in some parts. This fracture does not proceed in a straight line, but instead, changes direction in a few places. There is one fracture located near the bottom of the face that connects the three just described. This fracture is parallel to the bottom face, instead of perpendicular like the others. It does not extend from one side of the face to the other, but instead ends when it runs into the two outside fractures. This fracture ranges from being open to closed. There is a large, mostly closed fracture that runs from the west face across to the east. It is roughly parallel to the bottom face and goes through each of the large perpendicular fractures. There is another fracture toward the top of the face that extends from the west to east as well. This fracture is mostly closed with only a few places that remain open. This face resembles a road map in the way that the fractures run into one another. There are numerous small open and closed fractures that connect between some of the larger fractures. On the side between this face and the west face, there is a chunk missing, about $6 \mathrm{~cm}$ long and $3 \mathrm{~cm}$ into the block. The corner by the west and south faces has a piece missing as well. This one measures about $20 \mathrm{~cm}$ in length along the bottom face. In the corner by the east and bottom faces, there is a fracture zone that contains open and closed fractures that are oriented so that they curve around the corner. The positioning of the fractures looks as if a piece of this corner could break off easily. 


\section{North Face}

This face is similar to the south face because it consists mainly of open and closed fractures. There is a large fracture that extends from the top face almost to the bottom of the block. This fracture is open in some places, closed or filled in others, and it is roughly perpendicular to the top face. There is a closed fracture that runs from the east face to the west. It is located about $10 \mathrm{~cm}$ away from the bottom face and is parallel to it. There are several mostly closed fractures that are parallel to the top and bottom faces and extend across most of the block. There is a fracture zone located in the corner by the bottom and west faces. This zone contains both open and closed fractures that intersect a lot. The majority of the closed fractures are oriented parallel to the top and bottom faces, whereas the majority of the open fractures are oriented perpendicular to the top and bottom faces. The corner formed by the intersection of the top, east, and north faces is basically missing. On the side of the bottom face, there is a series of pieces missing from the side of the block. These missing pieces measure about $3-4 \mathrm{~cm}$ in length and extend about $1-2 \mathrm{~cm}$ into the block.

Fig. A-1. Fracture map of top, south, and east sides of small block 2 .

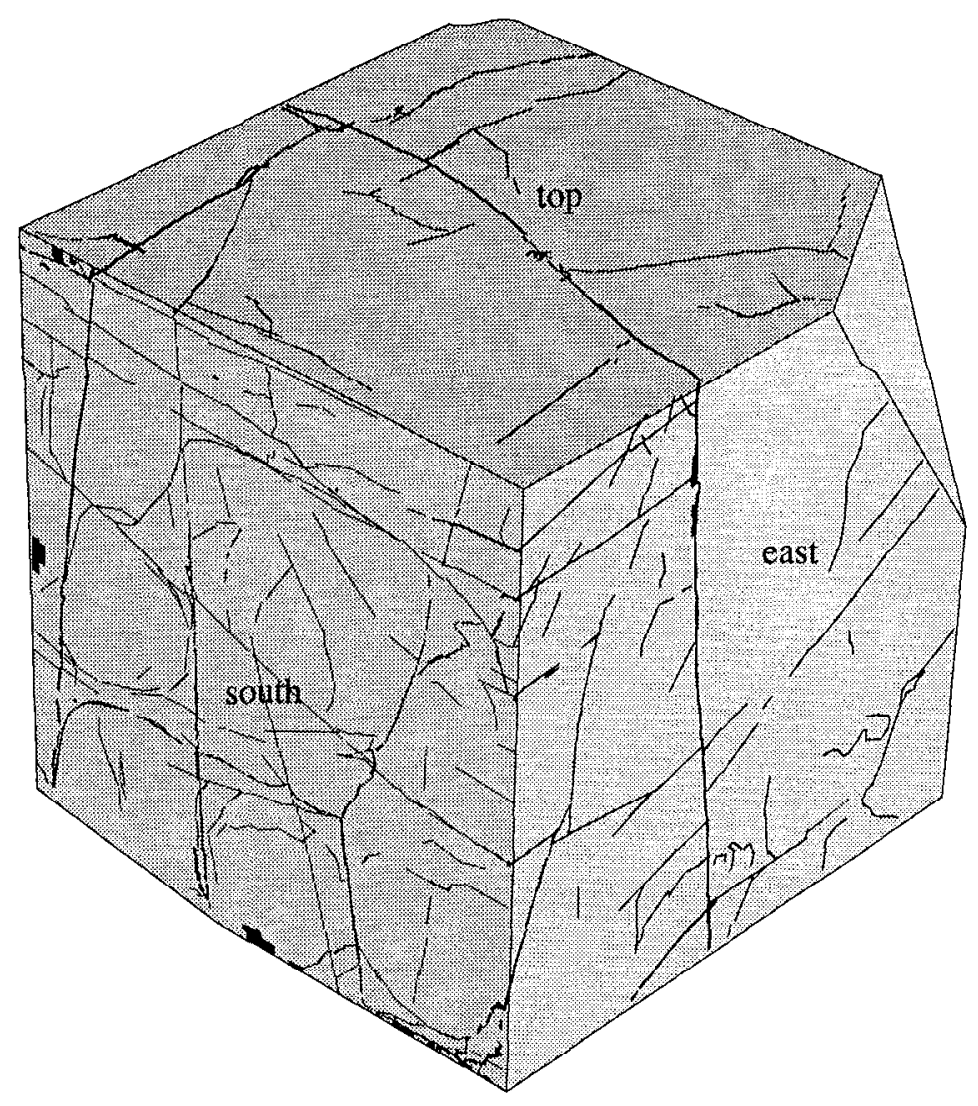




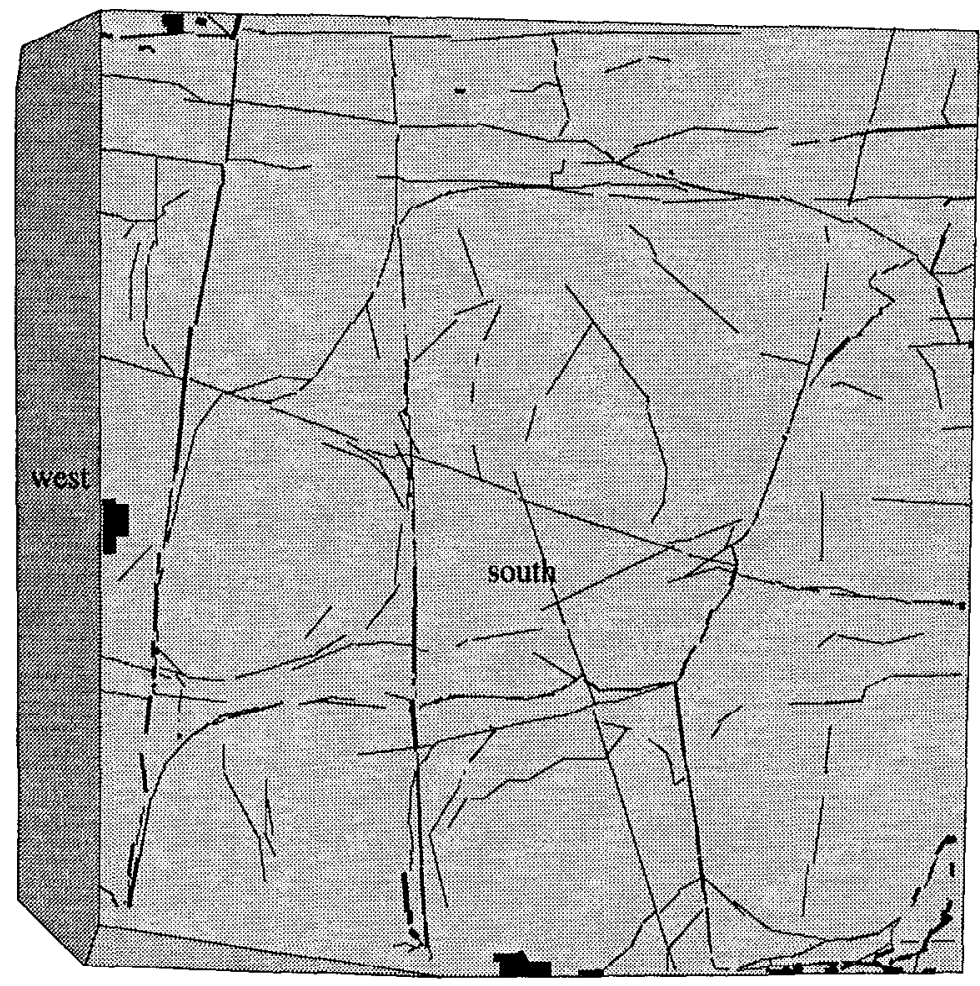

Fig. A-2. Fracture map of south side of small block 2 .

\section{Observations (SB-3)}

\section{West Face}

The vugs and cracks are co-planar and perpendicular to the top and bottom faces. There is a fracture zone that extends about $3 / 4$ of the way down the face and has a slight angle of about $75-80^{\circ}$ relative to the bottom. This zone consists of open and closed fractures that could almost be connected in a line. Many of the fractures in this zone have a mineral coating that is lining the sides and sometimes separating one fracture from another. There are several fractures on the bottom half of the block closest to the south side. Each has a length of about $4-5 \mathrm{~cm}$ and a width of about $0.5 \mathrm{~cm}$ and all are perpendicular to the top and bottom faces. These fractures also exhibit the mineral coating the fracture openings. 


\section{North Face}

There is a large oval vug located at the center of the face and about six or seven centimeters down from the top. The vug is at an angle of approximately $60^{\circ}$ relative to the bottom and has a length of $5 \mathrm{~cm}$ and a width of $1.5 \mathrm{~cm}$. This large vug contains some mineral coating the outsides. There is an absence of the co-planar perpendicular fractures that are present in the west, top, and bottom faces. There are relatively few fractures, only small vuggy zones. There are two fractures that meet at right angles to one another a few centimeters below the large oval vug. There are two fracture zones, one located about $12 \mathrm{~cm}$ below the large oval vug, and the other in the corner by the top and west faces. Each of these zones contains some mineral filling in the area between and around the fractures.

\section{Top Face}

There are several large vugs and cracks that are parallel to each other and almost perpendicular to the west and east faces. This is consistent with the orientation of the fractures and vugs on the west and top face. Most of the fractures and vugs are slightly tilted at an angle of about $75-85^{\circ}$ relative to the west side. There are 4-5 large fractures that measure approximately $7-8 \mathrm{~cm}$ in length. There is a fracture zone that extends across the face perpendicular to the west and east faces. This zone contains several fractures and vugs that could almost be connected in a line at an angle of about $75^{\circ}$. These fractures and vugs have some mineral lining the openings. In the center by the west face, there is a vuggy zone that contains two noticeable vugs measuring about $8 \mathrm{~cm}$ in length. Both contain a mineral coating that lines the openings and has partially filled in the fracture or vug. There are a few other small fractures and vugs randomly located throughout the face that also contain the mineral filling.

\section{Bottom Face}

This face resembles the top by way of the orientation and length of the fractures. There are several vugs and fractures that run perpendicular to the west and east faces. This is consistent with the orientation of the fractures and vugs on the west and bottom faces. There is a large fracture zone that is located close to the north face. One of the large fractures has a length of about $13 \mathrm{~cm}$, and it is at an angle of about $100^{\circ}$ relative to the west side. Roughly parallel to that fracture are two others that have lengths of about $6-7 \mathrm{~cm}$. There is a vug located a few 
centimeters away from the east side and about $7 \mathrm{~cm}$ away from the north side and oriented at the same angle as the other fractures. There is another fracture zone that is located at the corner of the south and west faces. There are several fractures that are parallel to one another and oriented perpendicular to the west and east faces. Each of these fractures has an approximate length of $5 \mathrm{~cm}$. This face has a large amount of the mineral filling that connects a lot of the fractures and lines the openings of the small vugs.

\section{South Face}

This face contained very few fractures, and the few that were present did not exhibit the co-planar fracture characteristic that some of the other faces showed. There were many vugs, mainly concentrated in the half of the block closest to the bottom face. There was one large circular vug located towards the bottom and east faces. It had a diameter of about $4 \mathrm{~cm}$, and there were several fractures a few centimeters long extending from the vug. There was some mineral material lining the sides of the vug, but the majority of it was open. On the corner between this face and the east face, there are several missing pieces that seem to have been chipped off the side. This occurred near the bottom face and only extended about a centimeter in. There was a large vuggy zone located towards the west side and a few centimeters above the circular vug. Much of this zone consisted of small vugs that had some mineral filling in between the vugs, which is often the only thing separating the small vugs. There is a large oval vug located between the anchor holes for channel \#13. The vug has an approximate length of $5 \mathrm{~cm}$ and a width of $1.5 \mathrm{~cm}$. There is a large crack that is located to the right of the oval vug and has an orientation of $105^{\circ}$ relative to the bottom face and a length of $7 \mathrm{~cm}$. There are a few small vugs located on the half of the block closest to the top face, and each has a diameter of about one centimeter.

\section{East Face}

This face contained many closed fractures, but very few open ones. Even with the closed fractures, this face also did not exhibit as many co-planar parallel fractures as some of the other faces did. The closed fractures were randomly aligned and distributed along the half of the face that is closest to the south side, with only a few closed fractures aligning perpendicular to the top and bottom faces. On the half that is closest to the north side, the fractures did align themselves perpendicular to the top and bottom faces. This is consistent with what is observed on some of the other 
faces. There are three noticeable vugs that are located on the half of the face closest to the top. The largest of the three is toward the south face. It has a length of $9.5 \mathrm{~cm}$ and a width of $1.5 \mathrm{~cm}$. The second vug is located at the center toward the top. It has a length of $7 \mathrm{~cm}$ and a width of $1 \mathrm{~cm}$. The last vug is toward the top and north faces. It has a length of $4 \mathrm{~cm}$ and a width of $0.5 \mathrm{~cm}$. Each of these vugs is perpendicular to the top and bottom faces. The bottom half of the face has relatively few fractures and vugs.

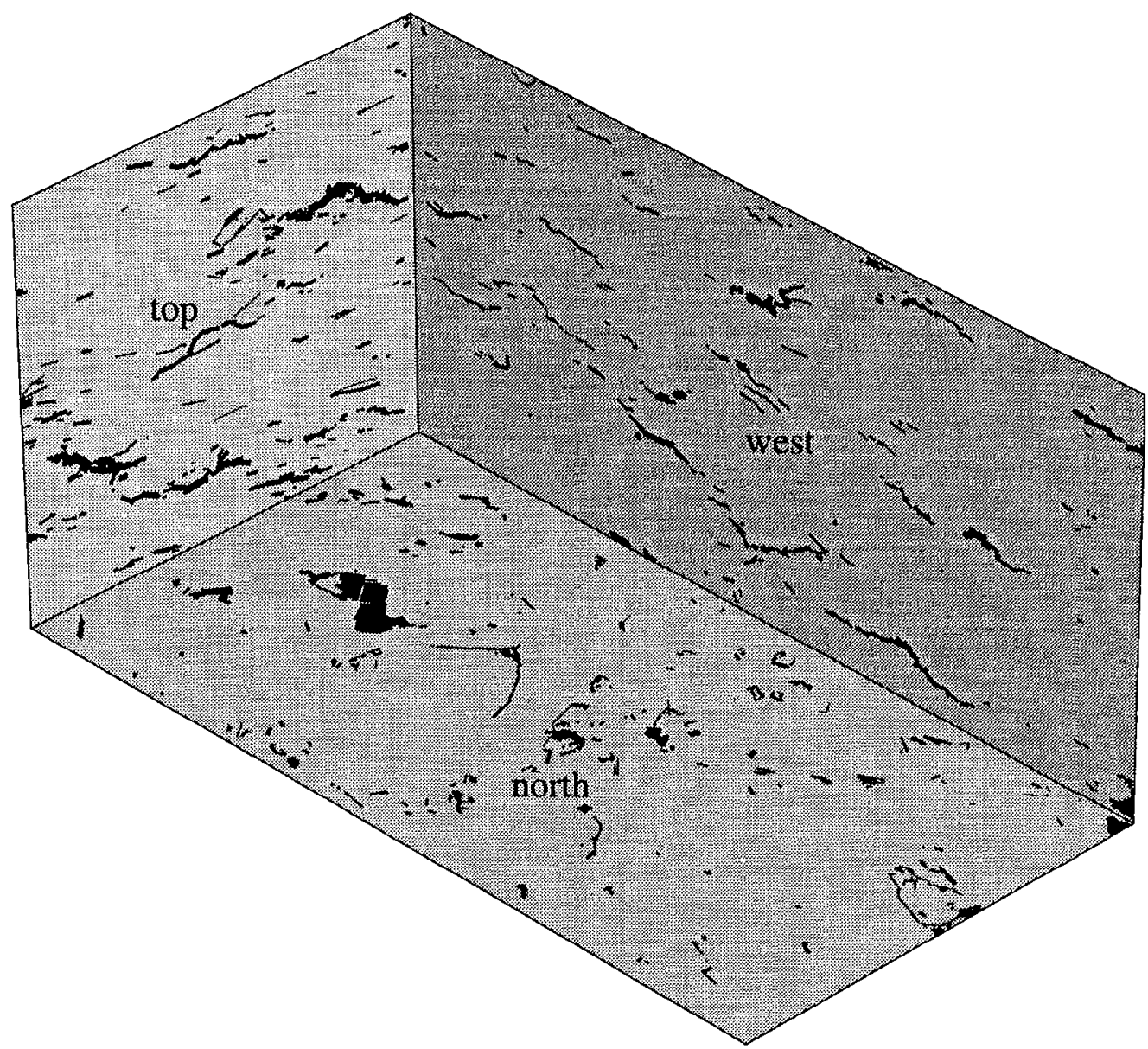

Fig. A-3. Fractures and vugs on the west, north, and top faces of small block 3. Notice the alignment of the fractures and vugs on the west and top faces. 


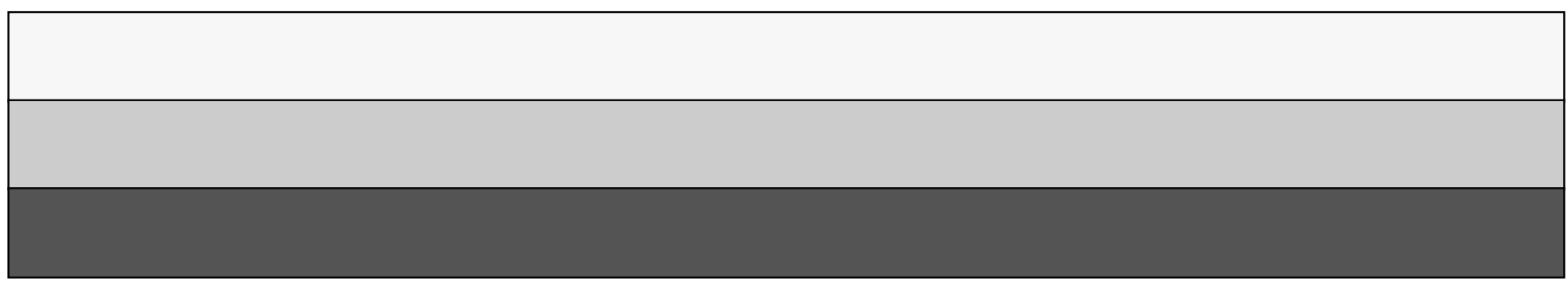

